\title{
Forward Guidance Contracts
}

\author{
CESIFO WORKING PAPER NO. 5375 \\ CATEgORy 7: MONETARy POLICY AND INTERNATIONAL FinANCE \\ MAY 2015
}

An electronic version of the paper may be downloaded

- from the SSRN website:

- from the RePEc website:

wWw.SSRN.com

Www.RePEc.org

- from the CESifo website:

www.CESifo-group.org/wp 


\title{
Forward Guidance Contracts
}

\begin{abstract}
We examine "Forward Guidance Contracts", which make central bankers' utility contingent on the precision of interest-rate forecasts for some time. Such Forward Guidance Contracts are a flexible commitment device and can improve economic performance when the economy is stuck in a liquidity trap. Utilizing the New Keynesian Framework, we establish the properties of simple renewable Forward Guidance Contracts and characterize the contracts that the government wants to offer repeatedly. These contracts create favorable tradeoffs between the efficacy of forward guidance at the zero bound and the reduced flexibility in reacting to future events, when the zero bound on nominal interest rates constrains the central banks' choice. We discuss how Forward Guidance Contracts can be used when there is uncertainty about natural real interest-rate shocks, a situation which typically calls for moderate incentive intensity. Finally we explore alternative contractual environments.
\end{abstract}

JEL-Code: E310, E490, E520, E580.

Keywords: forward guidance, zero lower bound, central banks, incentive contracts, transparency.

\author{
Hans Gersbach \\ Center of Economic Research at \\ ETH Zurich / CER-ETH \\ Switzerland-8092 Zurich \\ hgersbach@ethz.ch
}

\author{
Volker Hahn \\ Department of Economics \\ University of Konstanz \\ Box 143 \\ Germany - 78457 Konstanz \\ volker.hahn@uni-konstanz.de
}

Yulin Liu

Center of Economic Research at

ETH Zurich / CER-ETH

Switzerland - 8092 Zurich

liuyul@ethz.ch

This version: May 2015

We would like to thank Oliko Vardishvili and Martin Tischhauser for valuable comments on this paper. 


\section{Introduction}

\subsection{Motivation}

Announcing the future stance of monetary policy has become a common component in the toolbox of central banks. The Bank of England and the Federal Reserve, for instance, have started to make public statements about their future actions. In particular, they have been pledging since 2012 and 2013, respectively, to refrain from increasing the short-term interest rates until the economic situation has improved. ${ }^{1}$

A broad academic and political debate has emerged on the potential and limits of such forward guidance. One challenging phenomenon has attracted particular attention: If an economy is hit by adverse shocks - e.g. by a negative shock to financial intermediation - and the central bank's reaction is constrained by the zero bound on nominal interest rates, such a downturn will cause excessively high costs. Figuring out how the central bank can reduce the economic costs of this downturn and can provide appropriate stimulus for the economy is a major challenge for monetary policy - and the subject of ongoing debate.

Several solutions to this problem have been proposed in the academic literature. Krug$\operatorname{man}(1998)$, Eggertsson and Woodford (2003), and recently Werning (2011) have investigated how commitments to keeping the nominal interest rate at zero for several periods - even beyond the duration in the discretionary solution - can generate favorable tradeoffs between current downturns and a future boom and can lower the intertemporal costs of adverse shocks.

\subsection{Approach and results}

In this paper we introduce the concept of Forward Guidance Contracts as an alternative and flexible commitment device to address this issue. In particular, we combine the standard New Keynesian Framework to examine the zero-bound problem ${ }^{2}$ under Forward Guidance Contracts. These contracts work as follows: Central bankers announce

\footnotetext{
${ }^{1}$ The initial pledges in December 2012 and August 2013, respectively, were conditioned on unemployment rates. Since then a variety of other measures have been used (see Economist (2014)).

${ }^{2}$ See Eggertsson and Woodford (2003) and Eggertsson (2003).
} 
their policy rate for a particular time frame. The central bankers' intertemporal utility is made dependent on the accuracy of this forecast. For instance, their pay or pension could monotonically decrease with the size of the deviation of the actual interest-rate choice from the forecast.

The essential idea of Forward Guidance Contracts is that they create partial commitment. Central bankers will try to stick to the forecast but still deviate to some extent if future developments make such a commitment too costly. We show that Forward Guidance Contracts can yield favorable tradeoffs between the efficacy of forward guidance in helping to jump-start the economy and a reduction of flexibility in responding to future developments.

At a more specific level, our results are as follows: First, we integrate simple renewable Forward Guidance Contracts set by the government into the New Keynesian Framework. Second, we analyze and characterize optimal Forward Guidance Contracts when the government commits to using such contracts in downturns. Under these contracts, the central banker sets interest rates in a downturn at zero and sets interest rates immediately after the downturn at levels lower than the ones he would set under discretion. The induced higher levels of inflation and output at the beginning of the future boom feed back into higher current output and inflation. Third, we characterize the contracts the government chooses when it decides in each period whether to offer Forward Guidance Contracts or not. Fourth, we characterize Forward Guidance Contracts that yield an entire range of welfare gains for negative natural real interest-rate shocks when the contract parameters have to be chosen under a veil of uncertainty about such shocks. Typically, the optimal intensity of central bankers' incentives to stick to their forecasts is moderate in such circumstances. Fifth, we consider an alternative contractual environment in which Forward Guidance Contracts are signed at the beginning of a given period $t$, become effective immediately, last two periods, and do not constrain the interest-rate forecast in the contract. Such contracts can achieve welfare gains similar to one-period contracts. In addition, they can easily be extended to longer-term contracts, which can further improve welfare if the natural real interest-rate shock is extremely severe. 


\subsection{Literature}

Forward Guidance Contracts are a new type of contract for central bankers. They are based on earlier and recent literature. Walsh $(1995)^{3}$ proposes incentive contracts for central bankers and shows that such contracts can eliminate the inflation bias and can induce socially desirable shock stabilization when central bankers face a classic time-inconsistency problem. Gersbach and Hahn (2014) show that inflation forecast contracts that condition central bankers' pay on the precision of their inflation forecasts can improve welfare in a standard New Keynesian Framework when the economy faces cost-push shocks. In the present paper we discuss Forward Guidance Contracts in which the central bankers' utility is contingent on the accuracy of their own forecast regarding their future policy choices. It turns out that such Forward Guidance Contracts can create favorable tradeoffs between the commitment to zero interest rates when the economy is hit by a negative natural real interest-rate shock and the desired flexibility in increasing interest rates when the economy returns to normal levels.

The present paper belongs to a recent strand of literature on the benefits and costs of forward guidance and the optimal way of implementing it. Woodford (2012), Campbell (2008) and Gersbach and Hahn (2011) stress the social value of publishing central bank interest rate projections, and Campbell et al. (2012) and Gurkaynak et al. (2005) find that policy inclinations about the forward path of interest rates reveal information and can affect market expectations. ${ }^{4}$ Others, such as Lim and Goodhart (2011), are much more critical, suggesting that forward guidance may have little impact on expectations. We add to this literature by suggesting a concrete implementation of forward guidance and discuss ways in which Forward Guidance Contracts may help in jump-starting an economy.

\subsection{Organization of paper}

The paper is organized as follows: In the next section we present the model. To assess the potential of and challenges to Forward Guidance Contracts, the standard discre-

\footnotetext{
${ }^{3}$ The theory of incentive contracts was further developed in the influential papers by Persson and Tabellini (1993), Beetsma and Jensen (1998), Beetsma and Jensen (1999), Jensen (1997), Lockwood (1997), and Svensson (1997).

${ }^{4}$ Mirkov and Natvik (2013) find that central banks may be unwilling to deviate from previous interest-rate projections.
} 
tionary solution without Forward Guidance Contracts is presented in Section 3. In Section 4 we establish the properties and the welfare implications of optimal Forward Guidance Contracts. In Section 5 we investigate an alternative environment for Forward Guidance Contracts. A discussion and our conclusions are presented in Section 6 .

\section{Model}

\subsection{A general framework}

Our model combines Forward Guidance Contracts with the standard New Keynesian Framework to examine the zero-bound problem in a similar way to Eggertsson and Woodford (2003) and Eggertsson (2003). Time is discrete and indexed by $t=0,1,2, \ldots$. The IS Curve is described by

$$
x_{t}=\mathbb{E}_{t}\left[x_{t+1}\right]-\frac{1}{\sigma}\left(i_{t}-\mathbb{E}_{t}\left[\pi_{t+1}\right]-r_{t}\right)
$$

where $x_{t}$ denotes the $(\log )$ output gap in period $t$ and $\mathbb{E}_{t}\left[\pi_{t+1}\right]$ denotes the inflation rate in $t+1$ expected in $t$. Parameter $\sigma$ satisfies $\sigma>0, i_{t}$ is the nominal interest rate, and $r_{t}$ the natural real interest rate.

Following Eggertsson (2003), we consider two possible realizations of $r_{t}$, that correspond to two different states $s \in\{L, H\}$. With a slight abuse of notation, we write $r_{L}$ and $r_{H}$ for these realizations. We assume $r_{H}>0$ and $r_{L}<0$, which ensures that the zero lower bound typically binds in state $L$ but not in state $H$. In the following, we will say that the economy is in a "downturn" if the state is $L$. Similarly, we will use the term "normal times" to describe an economy in state $H$.

Like Eggertsson (2003), we consider a situation where the economy is initially in a downturn, i.e. $s=L$. In each period $t=1,2, \ldots$, the state will change to $s=H$ with constant probability $1-\delta(0<\delta<1)$ and then remain in this state forever. With probability $\delta$, the economy remains in the downturn. The Phillips Curve is

$$
\pi_{t}=\kappa x_{t}+\beta \mathbb{E}_{t}\left[\pi_{t+1}\right]
$$

with $\kappa>0$ and $\beta(0<\beta<1)$ as the common discount factor. 
The instantaneous social loss function is

$$
l_{t}=\frac{1}{2}\left(\pi_{t}^{2}+\lambda x_{t}^{2}\right),
$$

where $\lambda>0$. Future losses are discounted by the factor $\beta$.

As explained in more detail in Appendix $\mathrm{H}$, we assume that the central banker shares the private agents' objectives and thus faces the loss function (3) in each period. In addition, he may face a Forward Guidance Contract characterized by parameter $b$, which implies that the central banker incurs utility losses $b\left(i_{t}-i_{t}^{f}\right)^{2}$ when the interest rate he has chosen, $i_{t}$, differs from the level stipulated in the contract, $i_{t}^{f}$. We assume in the following that the level of interest rates stipulated in the contract ${ }^{5}$ is zero, i.e. $i_{t}^{f}=0$. First, this is broadly in line with current forward guidance practices of central banks in different countries. Second, it is straightforward to show that level zero is the optimal non-negative level for interest-rate forecasts.

In Appendix $\mathrm{H}$ we provide a foundation of the central banker's utility function when the government offers him a wage contract composed of a fixed wage and a variable component increasing with the accuracy of the interest-rate forecast and hence decreasing with $\left(i_{t}-i_{t}^{f}\right)^{2}$. The parameter $b$ - chosen by the government acting as contract designer - measures the intensity of incentives provided by the Forward Guidance Contract.

\section{$2.2 \quad$ Forward Guidance Contracts}

For the moment we will focus on simple renewable Forward Guidance Contracts that may be chosen by the government and affect the central banker's incentives in the subsequent period. In particular, we will consider two scenarios. In the first scenario, we will examine the implications of Forward Guidance Contracts under the assumption that the low realization of the natural real interest rate, $r_{L}$, is known when contract parameter $b$ is determined. Later, we will also examine a second scenario where $r_{L}$ is unknown when $b$ is selected.

\footnotetext{
${ }^{5}$ In Section 5 we analyze Forward Guidance Contracts in which the forecast is not part of the contract and is chosen by the central banker himself.
} 
More precisely, we assume in the first scenario that the government chooses $b$ at an exante stage. In all periods, it can only offer contracts with this parameter. In a particular period $t=0,1,2, \ldots$, the sequence is as follows: First, the current state $s \in\{H, L\}$ is realized and becomes common knowledge. Second, the government decides whether to sign a new Forward Guidance Contract with given parameter $b$ (henceforth $\mathrm{FGC}(b)$ ), which will be effective in period $t+1$. Third, the private sector forms its expectations about inflation and output in period $t+1$. Also, the central banker selects the nominal interest rate $i_{t}$ to minimize his losses, subject to (1) and (2). The central banker's loss function in period $t$ is influenced by a possible Forward Guidance Contract signed in period $t-1$. More precisely, it is

$$
l_{t}^{C B}=\frac{1}{2}\left(\pi_{t}^{2}+\lambda x_{t}^{2}\right)+\frac{1}{2} b i_{t}^{2}
$$

if a Forward Guidance Contract was signed in period $t-1$ and

$$
l_{t}^{C B}=\frac{1}{2}\left(\pi_{t}^{2}+\lambda x_{t}^{2}\right)
$$

otherwise. We assume that in the initial period $t=0$, a Forward Guidance Contract is effective. ${ }^{6}$ Figure 1 shows the sequence of events.

In Section 4.3 we consider the second scenario. In particular, we study Forward Guidance Contracts in a situation with uncertainty about parameter $r_{L}$ when contracts are designed. The only difference with the first scenario is that $b$ is chosen before the exact value of $r_{L}$ becomes known.

\section{Discretion without Forward Guidance Contracts}

To have a benchmark for assessing the potential and the limitations of Forward Guidance Contracts, we briefly summarize in this section the standard discretionary solution in the absence of Forward Guidance Contracts. In the following we focus on Markov equilibria, i.e. all economic variables depend only on the current state of the economy $s \in\{H, L\}$.

In each period, the central bank discretionarily chooses the nominal interest rate as its policy instrument, taking both its own future behavior and the public's expectations

\footnotetext{
${ }^{6}$ This assumption is immaterial to our findings.
} 


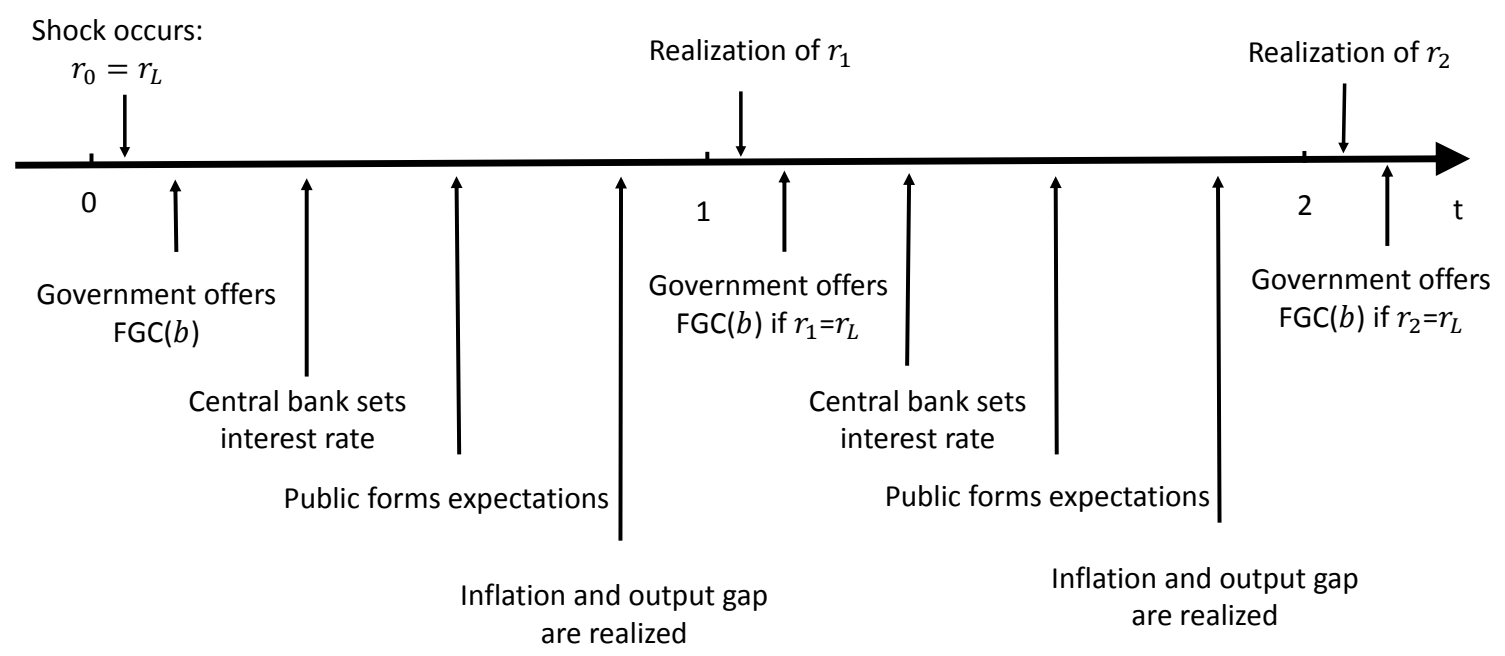

Figure 1: The sequence of events.

as given. In a Markov equilibrium there are only two possible realizations for inflation, the output gap, and the nominal interest rate. We use $\pi_{L}^{D}, x_{L}^{D}, i_{L}^{D}$ for the corresponding values in a downturn and $\pi_{H}^{D}, x_{H}^{D}$, and $i_{H}^{D}$ for normal times, where the superscript $D$ stands for "discretionary".

It is easy to compute the values of inflation and the output gap in normal times. When the natural real interest rate has returned to the positive value $r_{H}$, i.e. in period $t$ when $s=H$, optimal policy involves $i_{H}^{D}=r_{H}$. Therefore we obtain $x_{H}^{D}=0$ and $\pi_{H}^{D}=0$. Computing the equilibrium in the downturn is somewhat more involved. During the downturn, the zero lower bound is binding because of $r_{L}<0$. Hence, in periods when $s=L$, we obtain $i_{L}^{D}=0$. We note that $\mathbb{E}_{t}\left[\pi_{t+1}\right]=\delta \pi_{L}^{D}+(1-\delta) \pi_{H}^{D}=\delta \pi_{L}^{D}$ in a downturn, where we have used $\pi_{H}^{D}=0$, and we also note that the probability of the state remaining at $s=L$ is $\delta$. Analogously, we observe $\mathbb{E}_{t}\left[x_{t+1}\right]=\delta x_{L}^{D}$.

Inserting these expressions into (11) and (2) and solving for $\pi_{L}^{D}$ and $x_{L}^{D}$ yields

$$
\begin{aligned}
\pi_{L}^{D} & =\frac{\kappa}{\sigma(1-\delta)(1-\beta \delta)-\delta \kappa} r_{L}, \\
x_{L}^{D} & =\frac{1-\beta \delta}{\sigma(1-\delta)(1-\beta \delta)-\delta \kappa} r_{L} .
\end{aligned}
$$


Henceforth we assume that $\delta$ is sufficiently small for the denominator in the above equations to be strictly positive.

\section{Assumption 1}

Parameter $\delta$ satisfies

$$
\sigma(1-\delta)(1-\beta \delta)-\delta \kappa>0
$$

Assumption 1 imposes an upper bound on $\delta$, i.e. $\delta$ cannot be too large. For the parameter values in Table 1 below, this assumption is fulfilled for all $\delta<0.68$. Together with $r_{L}<0$, this assumption ensures that $\pi_{L}^{D}$ and $x_{L}^{D}$ are negative in a downturn. ${ }^{7}$ Throughout the paper we illustrate the properties of the economy using the following set of parameters: 8

Table 1: Parameter values.

\begin{tabular}{l}
\hline \hline$\beta=0.99$ \\
$\lambda=0.03$ \\
$\kappa=0.3$ \\
$\sigma=2$ \\
$r_{H}=0.02$ \\
\hline
\end{tabular}

\section{Forward Guidance Contracts}

In this section we analyze how the possibility of signing Forward Guidance Contracts affects the equilibrium. We assume that both the government and the central bank act under discretion. More specifically, upon observing the current state $s$, the government decides whether to sign a new contract, taking as given the central bank's decisions both in the current period and in all future periods, together with the possible existence of a contract for the current period. Then the central bank chooses its instrument subject to a possible Forward Guidance Contract, taking its own future decisions and the government's future behavior as given. We consider a Markov equilibrium, i.e. an equilibrium where the decision-makers' choices depend solely on payoff-relevant state

\footnotetext{
${ }^{7}$ For a discussion of sign reversals in the initial responses of inflation and output when the duration of an interest-rate peg is extended, see Carlstrom et al. (2012).

${ }^{8}$ The values $\beta=0.99, \lambda=0.03$, and $\kappa=0.3$ are taken from Gersbach and Hahn (2014). The values $\sigma=2$ and $r_{H}=0.02$ are taken from Eggertsson $(2006)$.
} 
variables, i.e. on $s \in\{H, L\}$ and the possibility that a contract was signed in the previous period.

For the moment we assume that the government will always choose a Forward Guidance Contract in a downturn and no contract in normal times. Later we will see that this behavior is indeed optimal for the government. We need to consider $2 \times 2=4$ different constellations because there are two different states $s \in\{H, L\}$ and there may be either an active contract $(C)$ or no active contract $(N)$. The corresponding levels of inflation will be denoted as $\pi_{H}^{C}, \pi_{L}^{C}, \pi_{H}^{N}$, and $\pi_{L}^{N}$. Analogous notation will be used for the different possible values of the output gap.

In normal times and in the absence of a Forward Guidance Contract, it is obvious that $\pi_{H}^{N}=x_{H}^{N}=0$ holds. Next we turn to the constellation where $s=H$ and a contract was signed in the previous period. Given the fact that in the next period, the output gap will be $x_{H}^{N}$ and inflation will amount to $\pi_{H}^{N}, \pi_{H}^{C}$ and $x_{H}^{C}$ can be determined with the help of (1) and (2) as follows:

$$
\begin{aligned}
\pi_{H}^{C} & =\beta \pi_{H}^{N}+\kappa x_{H}^{C}, \\
x_{H}^{C} & =-\frac{1}{\sigma}\left(i_{H}^{C}-\pi_{H}^{N}-r_{H}\right)+x_{H}^{N} .
\end{aligned}
$$

Using $\pi_{H}^{N}=x_{H}^{N}=0$, these equations simplify to

$$
\begin{aligned}
\pi_{H}^{C} & =\kappa x_{H}^{C}, \\
x_{H}^{C} & =-\frac{1}{\sigma}\left(i_{H}^{C}-r_{H}\right) .
\end{aligned}
$$

Minimizing $\frac{1}{2}\left(\pi_{t}^{2}+\lambda x_{t}^{2}\right)+\frac{1}{2} b i_{t}^{2}$ subject to (7) and (8) yields

$$
\begin{aligned}
\pi_{H}^{C} & =\frac{b \sigma}{\lambda+\kappa^{2}+b \sigma^{2}} \kappa r_{H}=\kappa f(b), \\
x_{H}^{C} & =\frac{b \sigma}{\lambda+\kappa^{2}+b \sigma^{2}} r_{H}=f(b), \\
i_{H}^{C} & =\frac{\lambda+\kappa^{2}}{\lambda+\kappa^{2}+b \sigma^{2}} r_{H},
\end{aligned}
$$

where we have introduced

$$
f(b):=\frac{b \sigma}{\lambda+\kappa^{2}+b \sigma^{2}} r_{H}
$$

We note that $f(b)$ is a monotonically increasing function with $f(0)=0$ and $\lim _{b \rightarrow \infty} f(b)=r_{H} / \sigma$. 


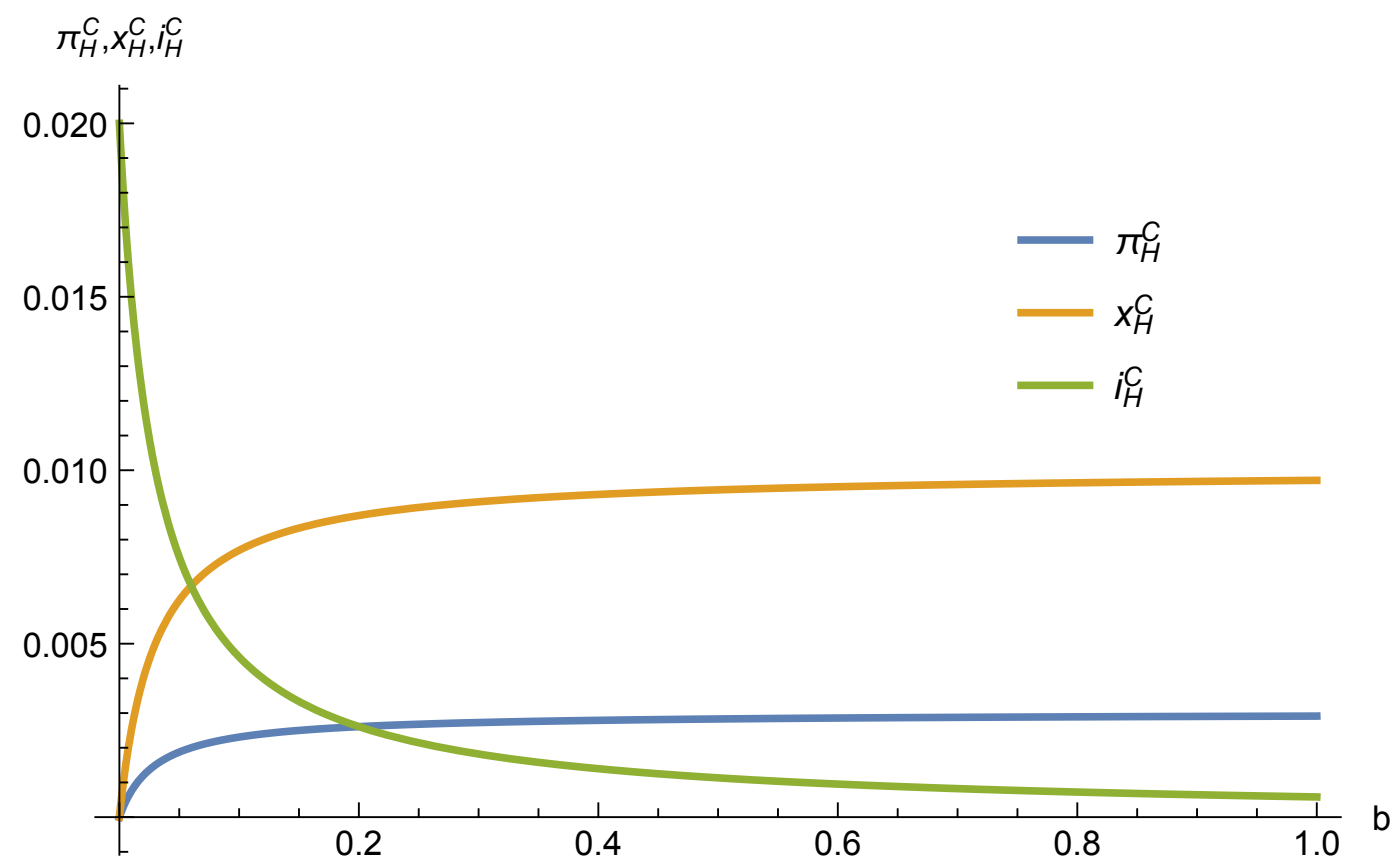

Figure 2: Inflation, output gap, and interest rate as a function of the value of $b$ in state $H$ with an active contract.

Equations (9) and (11) are useful in understanding why Forward Guidance Contracts are potentially welfare-improving. With the help of (11), we observe that the nominal interest rate in the first period after the downturn is a decreasing function of $b$ and that it is lower than the level that would prevail in the absence of a Forward Guidance Contract, $r_{H}$. Hence Forward Guidance Contracts enable the central bank to commit to expansionary monetary policy once the economy has left the downturn. Note that inflation will be higher if a Forward Guidance Contract is present in state $H$, which is shown by the fact that $\pi_{H}^{C}$ is an increasing function of $b .{ }^{9}$ Figure 2 shows how, under a Forward Guidance Contract, the nominal interest rate in state $H$ decreases when the incentive intensity $b$ increases. In turn, the inflation and output gap increase with $b$ in state $H$.

Finally, we examine inflation and output in a downturn. Because there is a constant probability $\delta$ of remaining in state $L$, expectations of inflation and output are

$$
\begin{aligned}
& \mathbb{E}_{t}\left[\pi_{t+1}\right]=\delta \pi_{L}^{C}+(1-\delta) \pi_{H}^{C}, \\
& \mathbb{E}_{t}\left[x_{t+1}\right]=\delta x_{L}^{C}+(1-\delta) x_{H}^{C} .
\end{aligned}
$$

\footnotetext{
${ }^{9}$ We observe that for $b=0,(9)-(11)$ entail the values of inflation, the output gap, and the nominal interest rate from the standard discretionary solution examined in Section 3
} 
We are now in a position to compute inflation and the output gap in the downturn. For the moment we assume that the zero lower bound is binding in the downturn, i.e. $i_{L}^{C}=0$. Later we will identify the range of values of $b$ for which this is actually the case. Further, we will show that the government's optimal choice of $b$ always lies within this range.

Using (1), (2), (9), (10), (12)-(14), and $i_{L}^{C}=0$ yields

$$
\begin{aligned}
& \pi_{L}^{C}=A f(b)+\pi_{L}^{D}, \\
& x_{L}^{C}=B f(b)+x_{L}^{D},
\end{aligned}
$$

where

$$
\begin{aligned}
A & :=\frac{\kappa(1-\delta)(\sigma(1+\beta(1-\delta))+\kappa)}{\sigma(1-\delta)(1-\beta \delta)-\delta \kappa}, \\
B & :=\frac{(1-\delta)(\sigma(1-\beta \delta)+\kappa)}{\sigma(1-\delta)(1-\beta \delta)-\delta \kappa}
\end{aligned}
$$

and $\pi_{L}^{D}$ and $x_{L}^{D}$ are defined in (4) and (5). Recall that, in line with Assumption 1 . the values $\pi_{L}^{D}$ and $x_{L}^{D}$, which would prevail without Forward Guidance Contracts, are strictly negative. Moreover, Assumption 1 entails $A>0$ and $B>0$. Together with $f^{\prime}(b)>0 \forall b \geq 0$, this implies that $\pi_{L}^{C}$ and $x_{L}^{C}$ strictly increase with $b$. Hence, for small $b$, Forward Guidance Contracts can cushion the harmful consequences of a downturn on the output gap and also mitigate the ensuing deflation. These beneficial effects are possible because Forward Guidance Contracts enable the central bank to commit to loose monetary policy after the downturn (see (9)-(11)). This commitment to expansionary policy after the downturn raises inflation expectations during the downturn (see (13) ) and thereby enables the central bank to implement a lower real interest rate $i_{t}-\mathbb{E}_{t}\left[\pi_{t+1}\right]=-\mathbb{E}_{t}\left[\pi_{t+1}\right]$ when the nominal interest rate is constrained by the zero lower bound. Figure 3 illustrates how, in state $L$, inflation and the output gap increase with incentive intensity $b$ under a Forward Guidance Contract.

Finally, we need to examine the circumstances in which our assumption that the zero lower bound is binding in a downturn is fulfilled under Forward Guidance Contracts. The following lemma, which is proved in Appendix A, establishes a sufficient condition for the zero lower bound to be binding: 


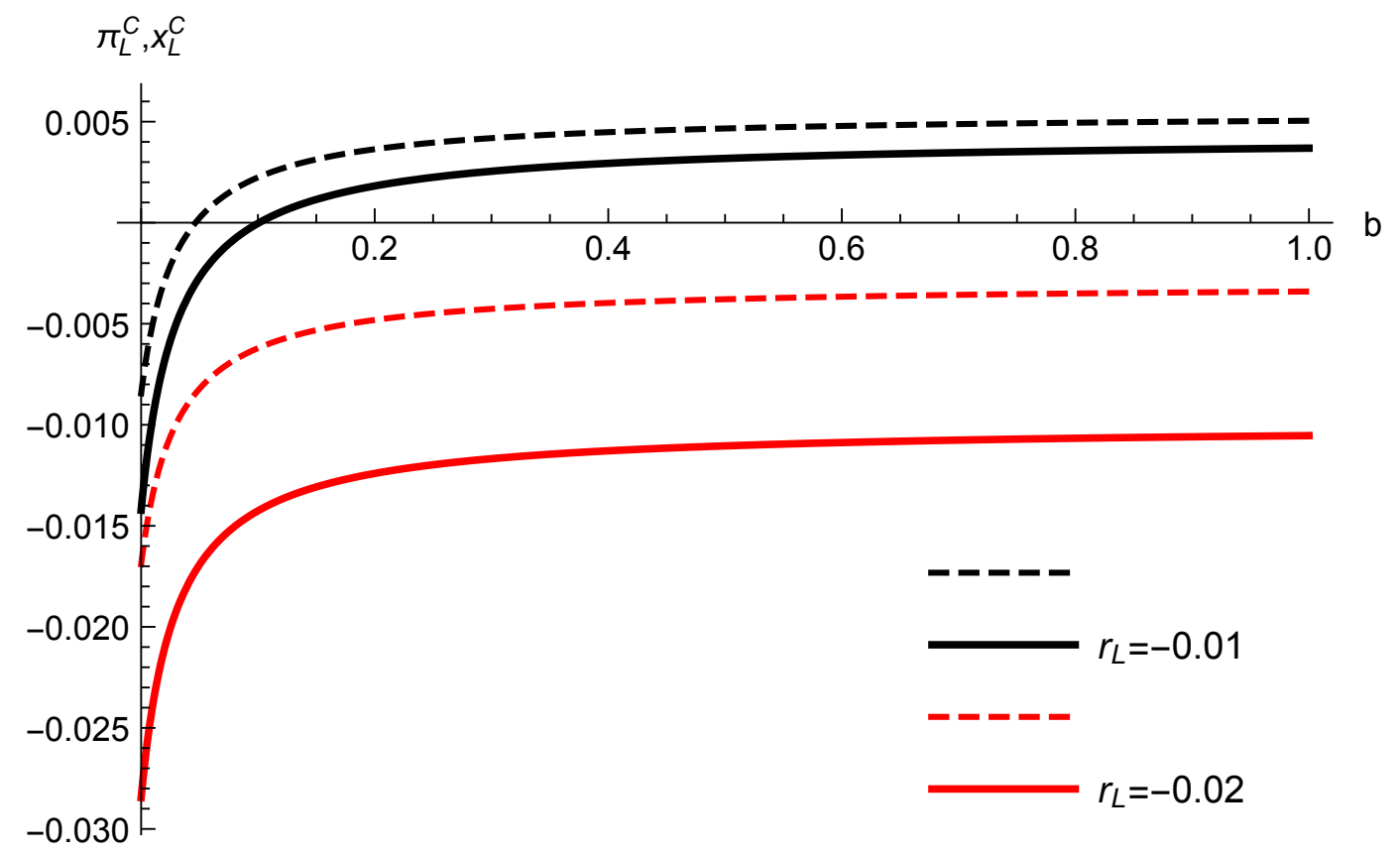

Figure 3: Inflation (dashed curves) and output gap (solid curves) as a function of the value of $b$ for different shock sizes.

\section{Lemma 1}

If

$$
f(b) \leq \frac{\kappa^{2}+\lambda(1-\beta \delta)}{\kappa(\kappa A+\lambda B)}\left|\pi_{L}^{D}\right|=: \hat{f},
$$

then the zero lower bound is binding in a downturn with Forward Guidance Contracts.

As (i) $f(b)$ monotonically increases with $b$, (ii) $f(0)=0$, and (iii) the right-hand side of the condition in the lemma is positive and does not depend on $b$, the lemma defines a critical value of $b$, henceforth denoted by $\hat{b}$, such that the zero lower bound is binding in state $L$ for all values of $b$ below this critical value. Note that this value will be infinite if the right-hand side of (19) is at least as large as $\lim _{b \rightarrow \infty} f(b)=r_{H} / \sigma$.

We thus obtain the following corollary:

\section{Corollary 1}

The zero lower bound is binding regardless of the value of $b$ when $r_{L} \leq \hat{r}_{L}$, where

$$
\hat{r}_{L}:=-\frac{(\kappa A+\lambda B)[\sigma(1-\delta)(1-\beta \delta)-\delta \kappa]}{\sigma\left[\kappa^{2}+\lambda(1-\beta \delta)\right]} r_{H} .
$$




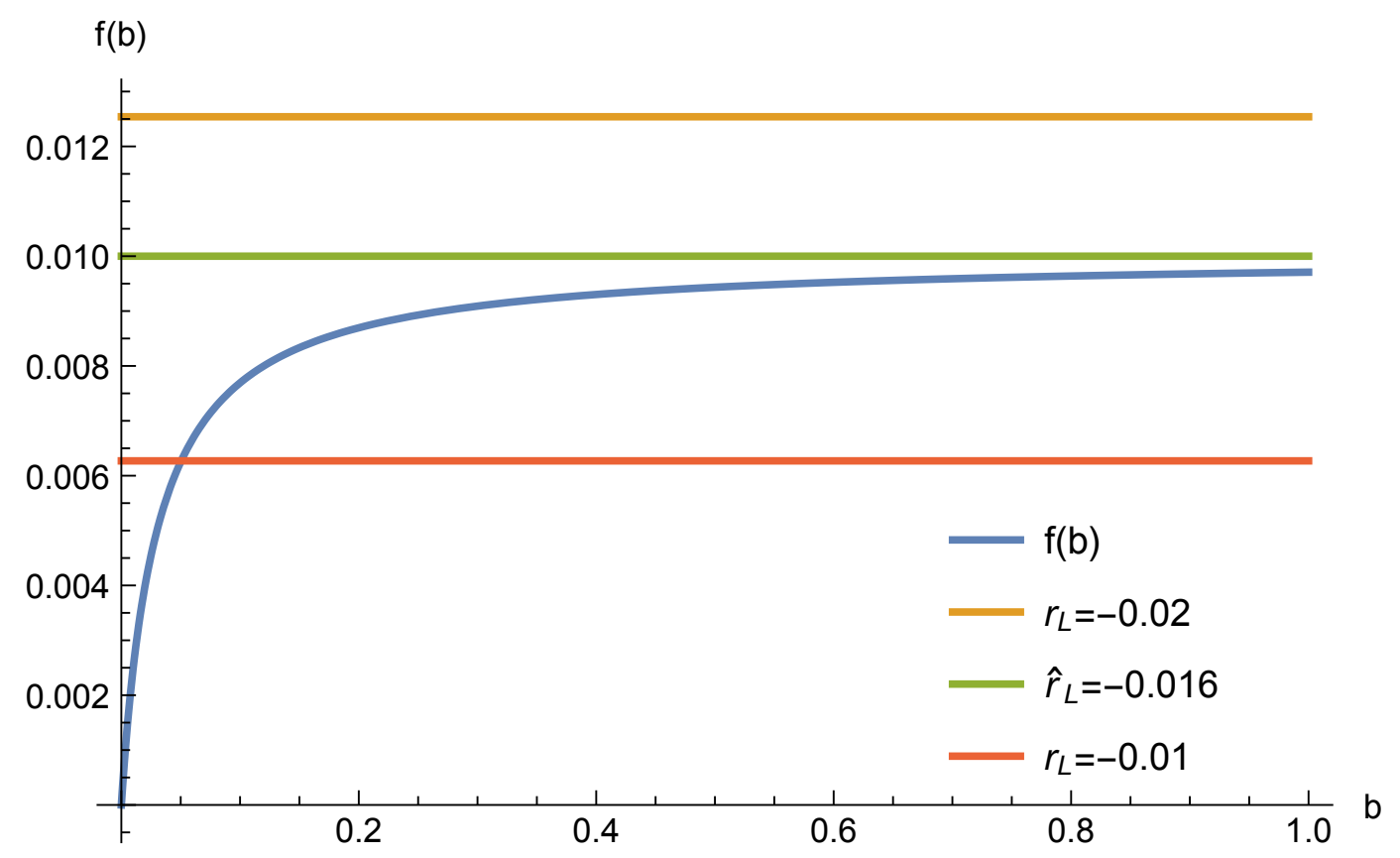

Figure 4: The function $f(b)$ and three horizontal curves representing the right-hand side of $(19)$ for different shock sizes.

We note that when the shock is severe, i.e. $r_{L} \leq \hat{r}_{L}$, the inflationary expectation induced by the Forward Guidance Contract is not large enough to lift the optimal nominal interest rate above zero, even if the value of $b$ is set at an extremely high level.

Figure 4 depicts the left-hand side and the right-hand side of $(19)$ from Lemma 1 for different values of $r_{L}$. In the case $r_{L}=-0.01$, a large value for $b$ induces positive inflation and output gap, as already shown in Figure 3 . Hence, (19) is only satisfied for low values of $b$. In the case $r_{L}=-0.02$, inflation and output gap in downturns are negative regardless of the value of $b$, as shown in Figure 3 . Correspondingly, (19) is always satisfied. Thus, in such a case, the zero lower bound is binding for all values of $b$.

In the following we restrict our attention to values of $b$ that satisfy the condition in the lemma. The justification for this assumption is that the government would never find it optimal to select a value of $b$ that would violate (19), which will be demonstrated in the next section. 


\subsection{Optimal contracts with commitment to contracting}

In this section we derive optimal Forward Guidance Contracts and thus determine the socially optimal value of $b$. In doing so, we continue to assume that the government always offers a Forward Guidance Contract in downturns and no contract in normal times. Later we will consider Forward Guidance Contracts in the absence of such commitments.

First we observe that in equilibrium per-period social losses can take only three different values:

$$
\begin{aligned}
& l_{L}^{C}=\frac{1}{2}\left(\pi_{L}^{C}\right)^{2}+\frac{1}{2} \lambda\left(x_{L}^{C}\right)^{2}=\frac{1}{2}\left(A f(b)+\pi_{L}^{D}\right)^{2}+\frac{1}{2} \lambda\left(B f(b)+x_{L}^{D}\right)^{2}, \\
& l_{H}^{C}=\frac{1}{2}\left(\pi_{H}^{C}\right)^{2}+\frac{1}{2} \lambda\left(x_{H}^{C}\right)^{2}=\frac{1}{2}\left(\kappa^{2}+\lambda\right)\left(x_{H}^{C}\right)^{2}=\frac{1}{2}\left(\kappa^{2}+\lambda\right)(f(b))^{2}, \\
& l_{H}^{N}=\frac{1}{2}\left(\pi_{H}^{N}\right)^{2}+\frac{1}{2} \lambda\left(x_{H}^{N}\right)^{2}=0,
\end{aligned}
$$

where we have used that $\pi_{H}^{N}=x_{H}^{N}=0,(9),(10)$, (15), and 16). Social losses expected in period 0 are given by

$$
V_{L}(C)=\sum_{t=0}^{\infty} \beta^{t} \delta^{t} l_{L}^{C}+\sum_{t=1}^{\infty} \beta^{t} \delta^{t-1}(1-\delta) l_{H}^{C}
$$

where the subscript $L$ stands for the current state of the economy and $C$ stands for the fact that a (C)ontract was signed in the previous period. In 23) we have utilized $l_{H}^{N}=0$ as well as the fact that (a) the probability of the economy being in a downturn is $\delta^{t}$ in all periods $t$ with $t \geq 0$ and (b) the probability that the economy has just left the downturn and hence a Forward Guidance Contract is still effective is $\delta^{t-1}(1-\delta)$ in all periods $t$ with $t \geq 1$. It is straightforward to rewrite (23) as

$$
V_{L}(C)=\frac{1}{1-\beta \delta}\left[l_{L}^{C}+\beta(1-\delta) l_{H}^{C}\right]
$$

Together with (20) and 21), 24 can be used to explain the tradeoff involved with Forward Guidance Contracts. First, $l_{H}^{C}$ is an increasing function of $b$, which is a consequence of the facts that $\pi_{H}^{C}=\kappa f(b)$ (see $(9)$ ), $x_{H}^{C}=f(b)$ (see $(10)$ ), $f(0)=0$, and $f^{\prime}(b)>0 \forall b \geq 0$. The interpretation of this observation is that Forward Guidance Contracts induce expansionary policy for one period once the downturn has ended. This is socially costly ex post. Second, $l_{L}^{C}$ is a monotonically decreasing function for 
small $b$. Hence Forward Guidance Contracts induce welfare gains in the downturn. This follows from the observation that the commitment to expansionary policy after the downturn increases inflation expectations during the downturn and thereby enables the central bank to implement lower real interest rates when the economy is stuck at the zero lower bound.

The socially optimal value of $b$ balances these costs and benefits. In Appendix $B$ we prove the following lemma:

\section{Lemma 2}

Suppose the government always offers a Forward Guidance Contract in state $L$ and never offers a contract in state $H$. Then the optimal value of $b, b^{*}$, can be determined in the following way:

1. If $r_{H} / \sigma>f^{*}, b^{*}$ is given by $f\left(b^{*}\right)=f^{*}$, where

$$
f^{*}:=\frac{A+\lambda B \frac{1-\beta \delta}{\kappa}}{A^{2}+\lambda B^{2}+\beta(1-\delta)\left(\lambda+\kappa^{2}\right)}\left|\pi_{L}^{D}\right| .
$$

At the optimal value of $b$, the zero lower bound is binding in equilibrium.

2. If $r_{H} / \sigma \leq f^{*}$, social losses decrease strictly with $b \forall b \geq 0$. In this case the zero lower bound is binding $\forall b \geq 0$.

It is instructive to conduct comparative statics with respect to $\left|r_{L}\right|$. For this purpose, observe that $f^{*}$ is a monotonically increasing function of $\left|r_{L}\right|$ because $\left|\pi_{L}^{D}\right|$ is a monotonically increasing function of $\left|r_{L}\right|$ (see (4)). As a result, the optimal value of $b, b^{*}$, which is given by $f\left(b^{*}\right)=f^{*}$ for $r_{H} / \sigma>f^{*}$, increases with $\left|r_{L}\right|$. This is plausible, as a higher value of $\left|r_{L}\right|$ corresponds to a larger shock and thus calls for stronger incentives. For $\left|r_{L}\right| \rightarrow 0$, the optimal value of $b$ converges to zero. Figure 5 illustrates

that $f\left(b^{*}\right)<f(\hat{b})$, which is straightforward to prove analytically. Thus, according to Lemma 1, the zero lower bound is binding with an optimal $\mathrm{FGC}\left(b^{*}\right)$.

Lemma 2 also defines a critical value of $r_{L}^{c}$ below which it is optimal to apply extremely harsh Forward Guidance Contracts.

\section{Corollary 2}

The optimal value of $b$ is infinite when $r_{L} \leq r_{L}^{c}$, where

$$
r_{L}^{c}:=-\frac{\left[A^{2}+\lambda B^{2}+\beta(1-\delta)\left(\lambda+\kappa^{2}\right)\right][\sigma(1-\delta)(1-\beta \delta)-\delta \kappa]}{\sigma[\kappa A+\lambda B(1-\beta \delta)]} r_{H} .
$$




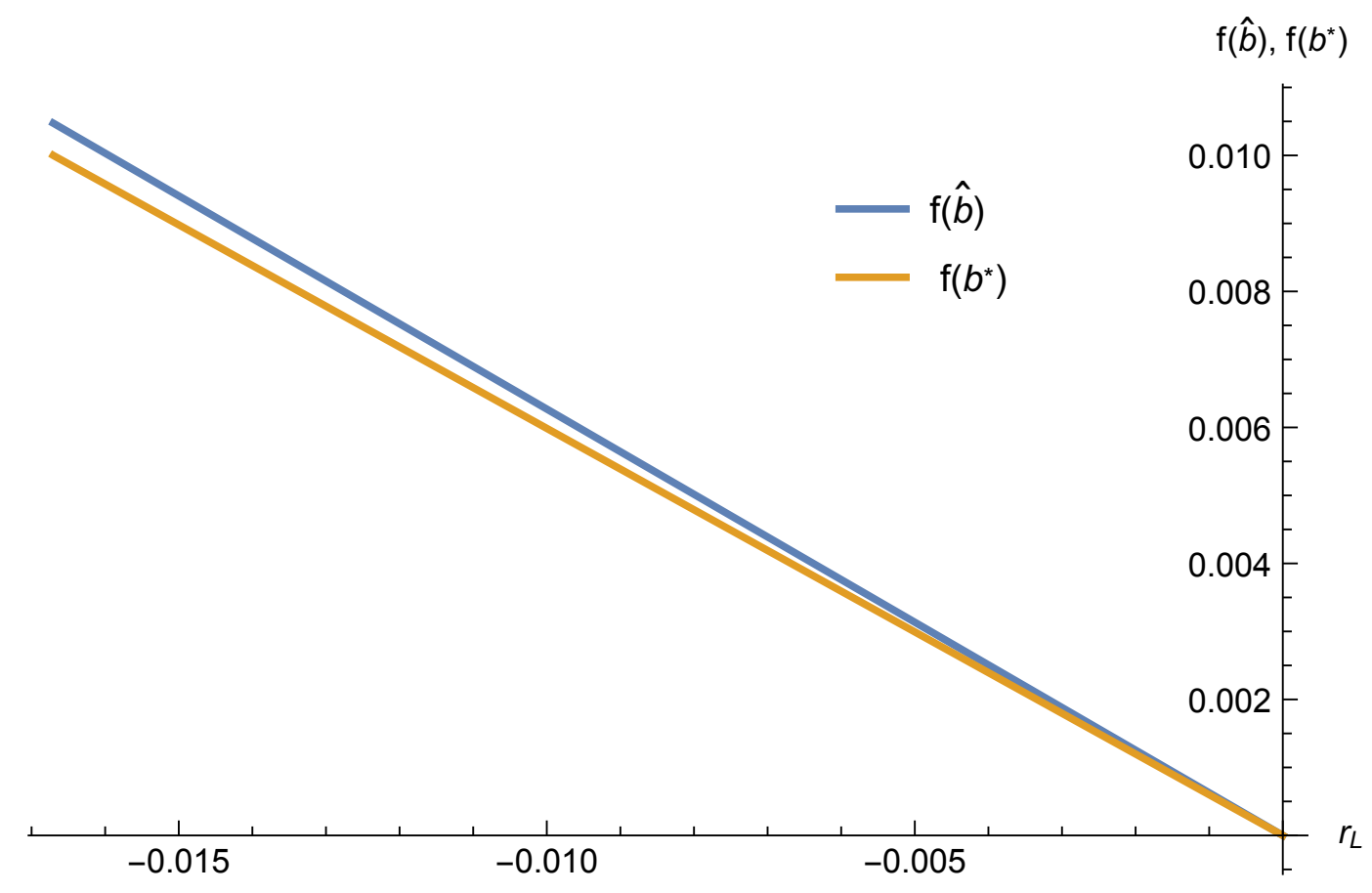

Figure 5: The values $f\left(b^{*}\right)$ and $f(\hat{b})$.

\subsection{Optimal contracts without commitment to contracting}

Up to now we have simply assumed that the government will behave in a certain way. It remains to show that this behavior is indeed optimal when the government decides in each period whether to offer the Forward Guidance Contract or not. The next lemma, which is proved in Appendix C, identifies a respective condition.

\section{Lemma 3}

The assumed behavior of the government, i.e. always signing a Forward Guidance Contract with $b=b^{*}$ in a downturn and refraining from signing a contract in normal times, is optimal if $f^{*} \leq 2 \tilde{f}$, where

$$
\tilde{f}:=\frac{A-P+\lambda(B-Q) \frac{1-\beta \delta}{\kappa}}{A^{2}-P^{2}+\lambda B^{2}-\lambda Q^{2}+\beta(1-\delta)\left(\kappa^{2}+\lambda\right)}\left|\pi_{L}^{D}\right| .
$$

$P$ and $Q$ are constants and given in Appendix C,

The lemma reveals that it is conceivable that for the optimal value of $b, b^{*}$ identified in Lemma 2, the government would not find it optimal to offer the contract. This may occur because the government takes its own future behavior and the behavior of private agents as given. This distinguishes the government's decision problem in a particular 


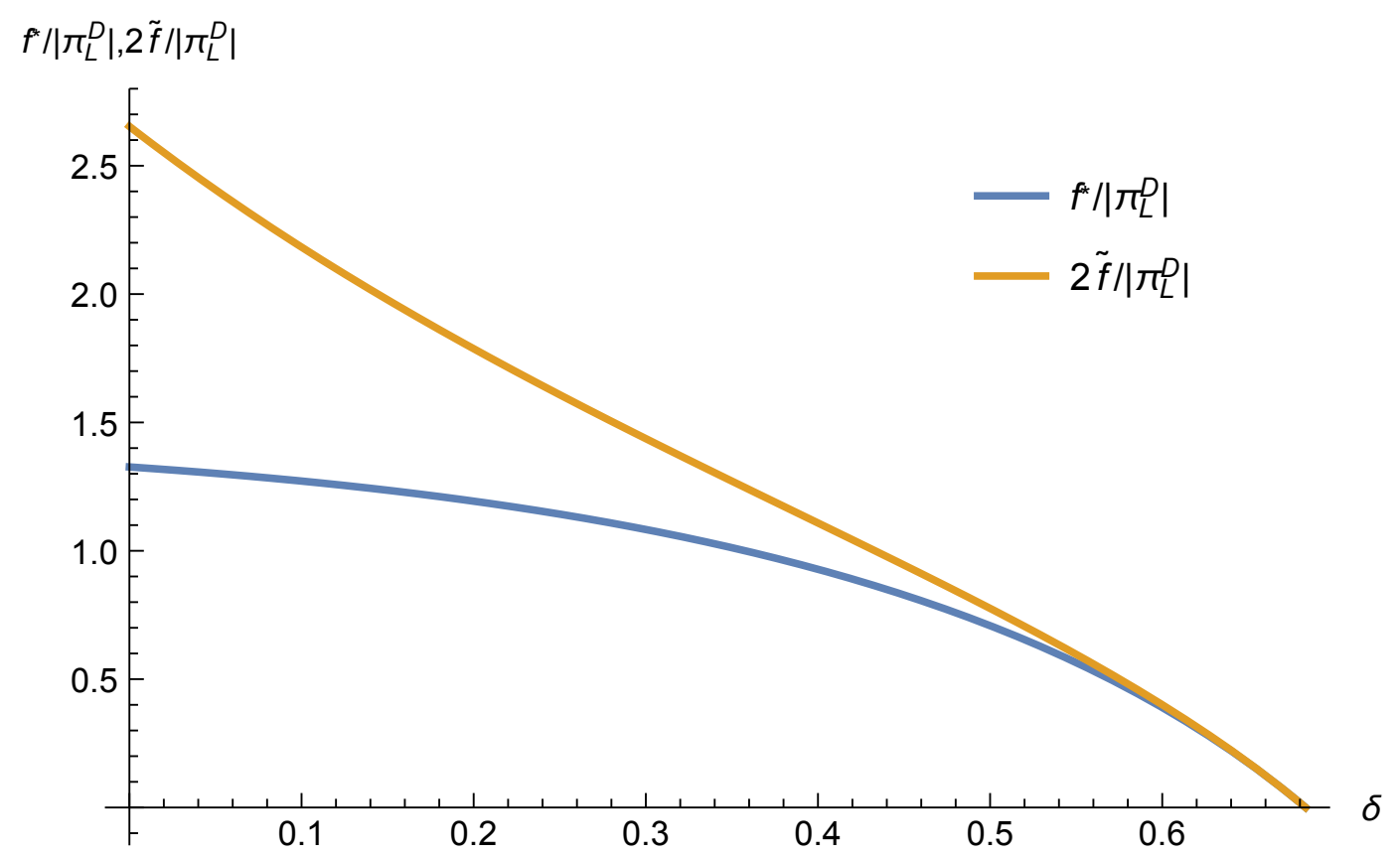

Figure 6: The values of $f^{*}$ and $2 \tilde{f}$, scaled by $\left|\pi_{L}^{D}\right|$, for the range of $\delta$ satisfying Assumption 1.

period from the problem in the ex-ante stage, where the government can choose $b$ for all future periods.

More specifically, when weighing up the costs and benefits of signing a Forward Guidance Contract in a particular period, the government will fully take the costs into account that would materialize in the next period, provided that the state were $H$. However, the government only considers a fraction of the benefits. This can be seen when we look at the well-known representation of the New Keynesian Phillips Curve, where current inflation is proportional to the expected discounted sum of all future output gaps

$$
\pi_{t}=\kappa \mathbb{E}_{t}\left[\sum_{i=0}^{\infty} \beta^{i} x_{t+i}\right],
$$

which directly follows from iterating (2). When the government signs a Forward Guidance Contract in period $t$, it only takes into account the effect this contract has for $\mathbb{E}_{t}\left[x_{t+1}\right]$. Because the government takes its own future behavior as given, it does not consider those benefits of Forward Guidance Contracts that result from the contracts' influence on output gaps farther away in the future, i.e. $\mathbb{E}_{t}\left[x_{t+i}\right] \forall i \geq 2$. Figure 6 shows 


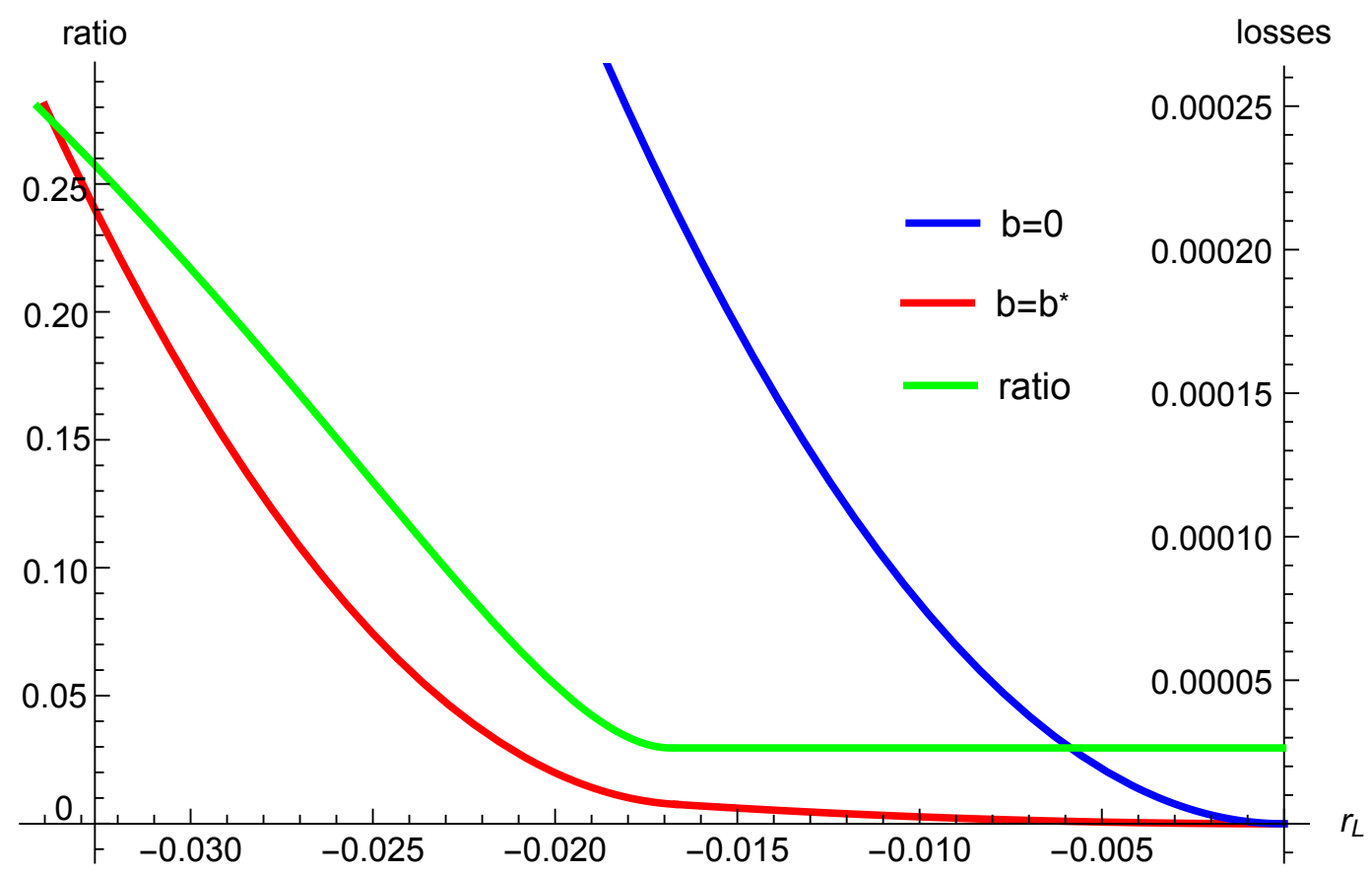

Figure 7: Discounted social losses with optimal $\mathrm{FGC}\left(b^{*}\right)$, in the discretionary case (right axis) and the ratio of these two discounted social losses (left axis).

that $f^{*} \leq 2 \tilde{f}$ is fulfilled in the range of $\delta$ that satisfies Assumption 1 at parameter values specified in Table 1 .

Despite the difficulty that a contract with $b^{*}$ may not be offered in equilibrium by the government, it is straightforward to determine the optimal value of $b$ for the case where the government optimally decides in each period whether to sign a contract for the next period or not.

\section{Proposition 1}

Suppose the government only offers a Forward Guidance Contract in each period if this is profitable. Then the optimal level of $b, b^{* *}$, can be determined in the following way:

1. For $2 \tilde{f} \geq f^{*}$ and $f^{*}<r_{H} / \sigma$, the optimal level of $b$ is given by $f\left(b^{* *}\right)=f^{*}$.

2. For $2 \tilde{f}<f^{*}$ and $2 \tilde{f}<r_{H} / \sigma$, the optimal level of $b$ is given by $f\left(b^{* *}\right)=2 \tilde{f}$.

3. For $2 \tilde{f} \geq r_{H} / \sigma$ and $f^{*} \geq r_{H} / \sigma$, we obtain $b^{* *}=\infty$. 
To close this section, we present in Figure 7 the discounted social losses with the use of a Forward Guidance Contract expected in period 0 (see (24)). The expected social loss with an optimal $\mathrm{FGC}\left(b^{*}\right)$ stays below the one in the discretionary case for all values of $r_{L}$. When we compare the ratio of social losses under Forward Guidance Contract with the social losses under discretion, we observe that a considerable welfare gain can be achieved with such contracts, as this ratio attains nearly 0.03 for $r_{L} \in\left(r_{L}^{c}, 0\right)$ and is still around 0.25 for a large negative natural real interest-rate shock. Hence we obtain quite favorable tradeoffs between the efficacy of Forward Guidance Contracts at the zero lower bound and the reduced flexibility in reacting to future events. Figure 7 also shows that the social loss with $\mathrm{FGC}\left(b^{*}=\infty\right)$ starts to increase considerably when $r_{L}<r_{L}^{c}{ }^{10}$

\subsection{Forward Guidance Contracts under uncertainty}

In this section we analyze the second scenario outlined in Section 2.2, asking whether Forward Guidance Contracts would also be desirable if $r_{L}$ were unknown at the point in time when the value of $b$ is chosen. For this purpose, we assume that $r_{L}$ is randomly distributed with commonly-known prior distribution. A further assumption we make is that the value of $r_{L}$ becomes known in the period when the downturn occurs.

First we observe that the possibility of Forward Guidance Contracts can never lead to lower expected levels of welfare - provided that $b$ is chosen optimally ex ante-because it would always be possible to select Forward Guidance Contracts with $b=0$, which would result in a scenario equivalent to the benchmark case without Forward Guidance Contracts.

Second, we show that Forward Guidance Contracts actually lead to strict increases in welfare. In particular, we show that $b$ can be chosen in such a way that Forward Guidance Contracts will improve welfare for all possible realizations of $r_{L}$.

\footnotetext{
${ }^{10}$ In such circumstances, welfare could be further improved by longer-term Forward Guidance Contracts, which we discuss in Section 5.3 .
} 


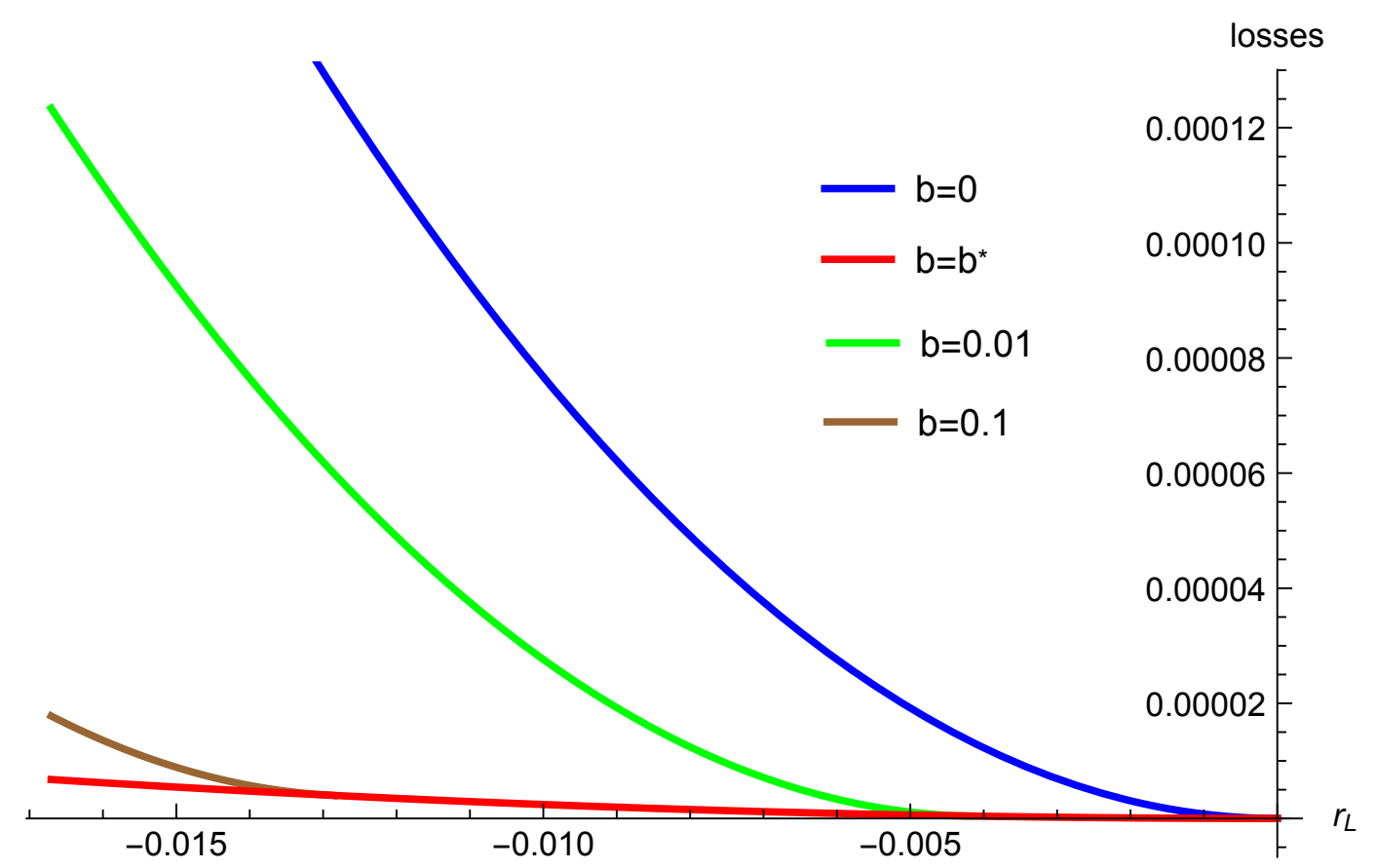

Figure 8: Discounted social losses under FGC, as a function of $r_{L}$, for different values of $b$.

\section{Proposition 2}

Suppose that $r_{L}$ is randomly distributed with a maximum possible realization $\bar{r}_{L}<0$. Then it is possible to select a value of $b$ such that (i) for each realization of $r_{L}$, the government offers the contract, and (ii) welfare conditional on this value of $r_{L}$ is strictly higher than in the benchmark case.

As the proposition implies that for all realizations of $r_{L}$ welfare is higher under Forward Guidance Contracts, the welfare level expected before the realization of $r_{L}$ becomes known is also higher under Forward Guidance Contracts than in the benchmark case without Forward Guidance Contracts.

In Figure 8, the blue and red curves represent the discounted social losses in the benchmark case and with an optimal FGC for each realization of $r_{L}$, respectively. The green curve represents the discounted social loss with $\bar{r}_{L}=-0.0042$ and the corresponding optimal $b=0.01$. The brown curve represents the discounted social loss with $\bar{r}_{L}=-0.0129$ and the corresponding optimal $b=0.1$. Intuitively, all of these curves representing the discounted social losses with a fixed value of $b$ are tangent to the red curve representing the discounted social loss with the optimal $b$. This figure 
also demonstrates that choosing the value of $b$ that is optimal for $\bar{r}_{L}$ improves social welfare for all $r_{L} \leq \bar{r}_{L}$. However, as the value of $b$ chosen ex ante is not the optimal one for the realization of $r_{L}$ below the upper bound $\bar{r}_{L}$, the social loss can be unnecessarily high when $r_{L}$ is significantly lower than $\bar{r}_{L}$.

When the maximum possible realization of the negative natural real interest rate is $r_{L}=0$, one can still construct Forward Guidance Contracts that will improve welfare for a wide range of natural real interest-rate shocks. ${ }^{11}$ Let us choose a value $\tilde{b}$ which is the optimal value of $b$ for some value $r_{L}=\tilde{r}_{L}$. As is demonstrated in Proposition 2 , it is socially desirable to $\operatorname{sign} \operatorname{FGC}(\tilde{b})$ for all the realizations $r_{L} \leq \tilde{r}_{L}$. Henceforth, we focus on the remaining range $r_{L} \in\left(\tilde{r}_{L}, 0\right)$.

In Appendix E we prove the following lemma:

\section{Lemma 4}

Given some value $\tilde{b}$ selected in period -1 , the zero lower bound is binding, and it is socially desirable to offer the $F G C(\tilde{b})$ when $r_{L} \leq a \tilde{r}_{L}$, where $a \in(0,1)$ is given in (67) in the proof.

Given the value $\tilde{b}$ that is optimal for $\tilde{r}_{L}$, the central bank would still set the nominal interest rate at zero when $r_{L} \in\left(\tilde{r}_{L}, a \tilde{r}_{L}\right)$. Intuitively, it is still socially desirable to offer the $\mathrm{FGC}(\tilde{b})$, as the induced inflation expectation is not unnecessarily large. If the size of the shock is small, i.e. $r_{L}>a \tilde{r}_{L}$, the induced inflation expectation in downturns that stems from $\mathrm{FGC}(\tilde{b})$ is unduly large. Then the central bank will set a positive interest rate to suppress the inflation boom in downturns.

We obtain the following proposition, proved in Appendix $\mathrm{F}$;

\section{Proposition 3}

Given some value $\tilde{b}$ selected in period -1, there exists an $\tilde{r}_{L}^{c}$ such that $F G C(\tilde{b})$ improves social welfare for all $r_{L}<\tilde{r}_{L}^{c}$, where $\tilde{r}_{L}^{c}>a \tilde{r}_{L}$ and $\tilde{r}_{L}^{c}$ is given in the proof.

Figure 9 shows how the threshold value $\tilde{r}_{L}^{c}$, below which the government offers the $\operatorname{FGC}(\tilde{b})$, decreases as $\tilde{b}$ increases. Hence, if the government wants to ensure welfare

\footnotetext{
${ }^{11}$ If we assumed a particular distribution of natural real interest-rate shocks, we could, of course, calculate the optimal Forward Guidance Contract that improves welfare in expectation. For instance, suppose that $r_{L}$ is distributed uniformly in $\left[\underline{r}_{L}, 0\right]$. Then there exists an optimal value of $b>0$ that minimizes expected welfare. Typically, the intensity of incentives for such exercises is moderate as long as $\underline{r}_{L}$ is not extremely low.
} 


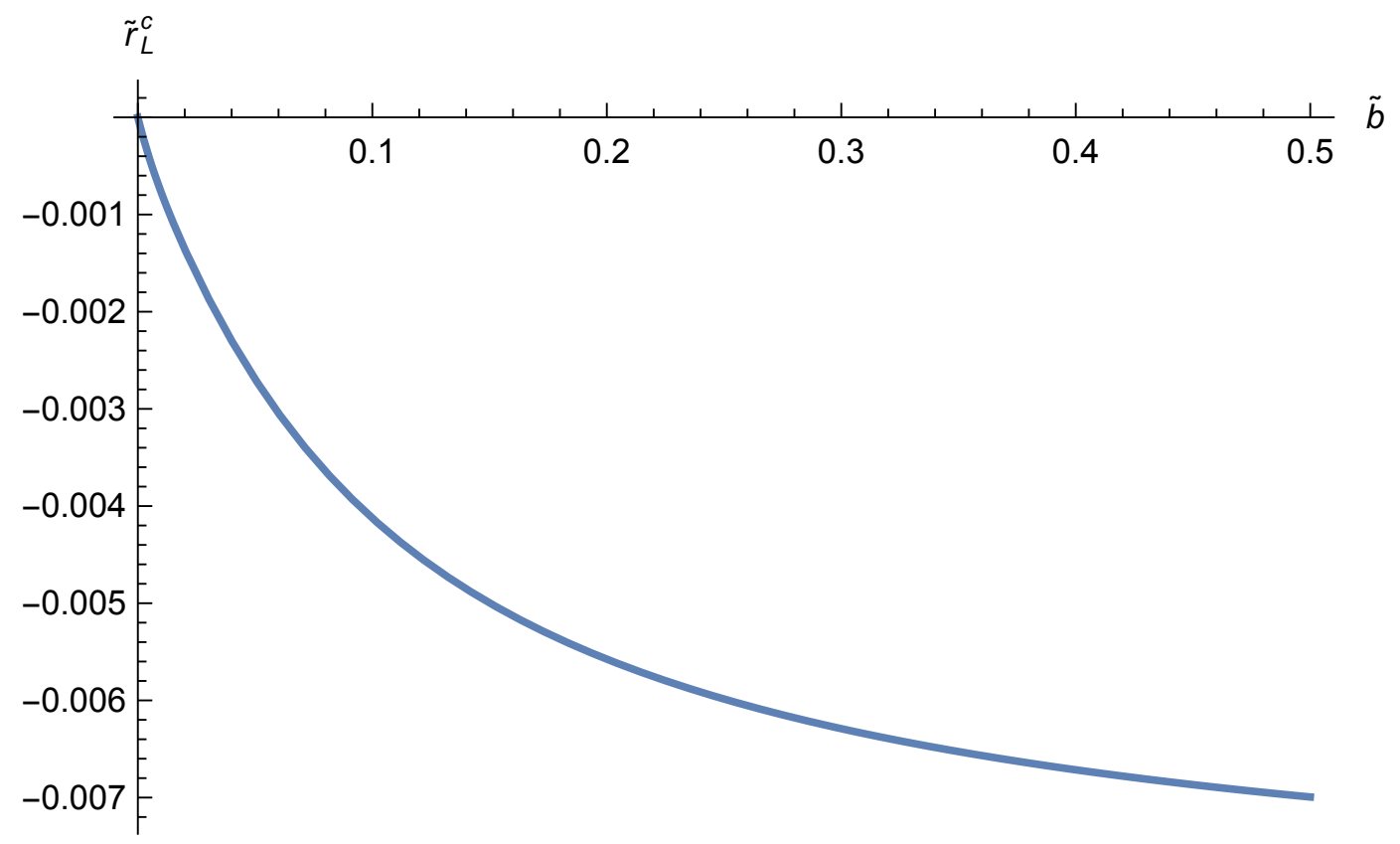

Figure 9: Impact of $\tilde{b}$ on the value of $\tilde{r}_{L}^{c}$.

gains for a very large range of realizations of negative natural real interest-rate shocks,

$\tilde{b}$ has to be set at moderate levels. As an example, consider $\tilde{b}=0.1$. In Figure 10, we show social loss under such a contract (dark line), coupled to those under discretion (blue line) and when the parameter $b$ can be tailored to the precise realization of shocks as given in Proposition 1. The critical threshold is $\tilde{r}_{L}^{c} \approx-0.004$, and Forward Guidance Contracts lead to lower social losses for all values below that. For natural real interest rates above $\tilde{r}_{L}^{c}$, Forward Guidance Contracts involve higher losses than under discretion.

\section{Alternative contractual environments and longer-term contracts}

\subsection{Two-period contracts}

So far, we have focused on simple renewable Forward Guidance Contracts signed in one period and becoming effective in the next. In this section, we explore a simple alternative: contracts that become effective immediately after signing and remain effective for one more period. 


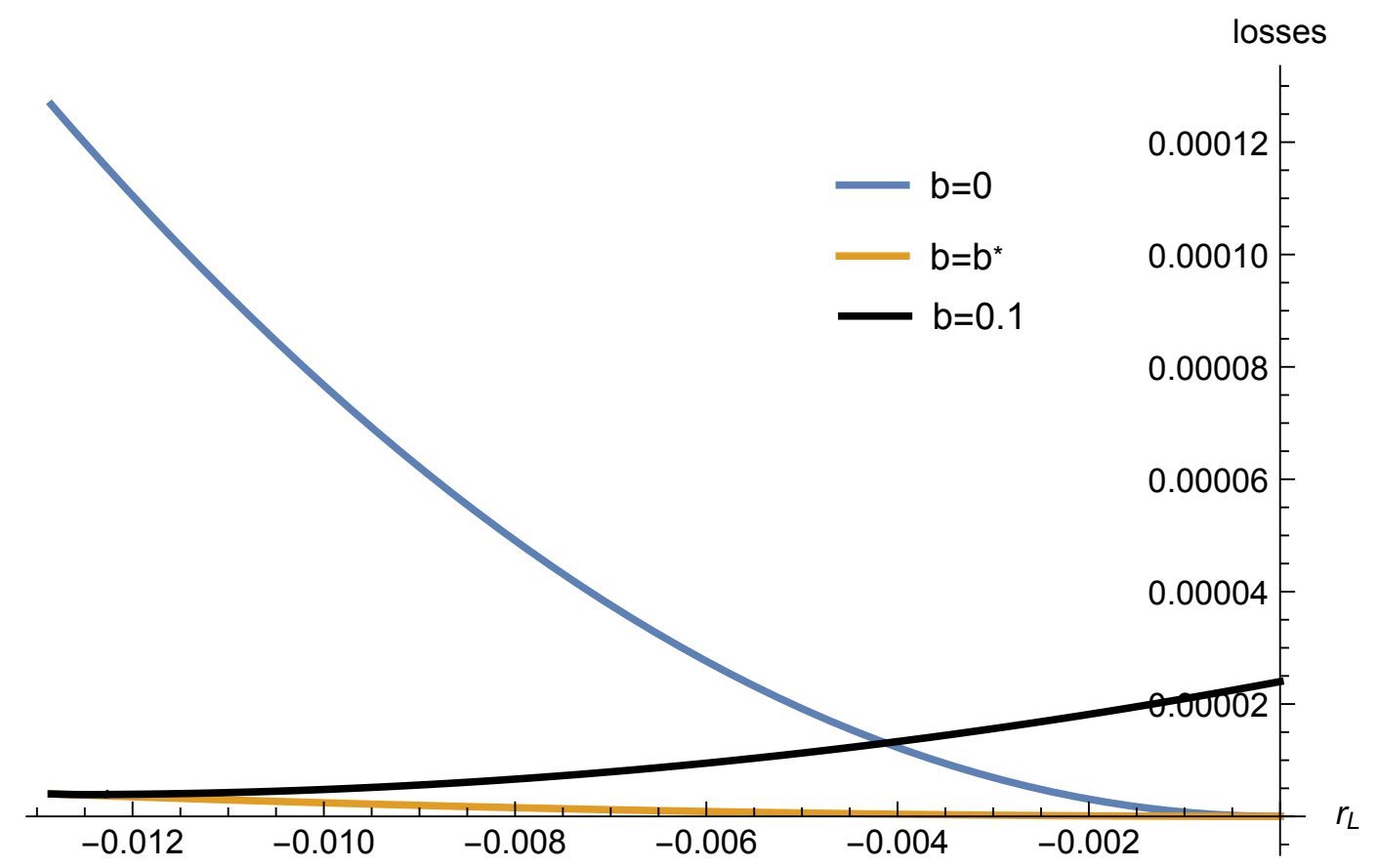

Figure 10: Discounted social losses with an FGC with $b=\tilde{b}=0.1$, under discretion and when $b$ is tailored to the realization of the shock.

First, however, we need to stress that both types of contract studied in Section 4 and in this section are the shortest (and simplest) contracts under which forward guidance can have an impact. ${ }^{12}$ Consider a simpler contract, i.e. one that only applies to the period in which it is written. Such a contract would never be signed in normal times. In the downturn, the central banker would also set zero interest rate in the absence of a Forward Guidance Contract. Hence, such a contract would only replicate the discretionary solution.

We use $\widehat{F G C}(b)$ to denote Forward Guidance Contracts that are signed at the beginning of a period $t$ and provide incentives for central banks to stick to their forecast in periods $t$ and $t+1$. As before, these contracts are renewed and repeatedly applied as long as the economy is in the downturn. While $\mathrm{FGC}(b)$ and $\widehat{\mathrm{FGC}}(b)$ can achieve similar welfare gains $^{13}, \widehat{\mathrm{FGC}}(b)$ differs from $\mathrm{FGC}(b)$ in two important respects. First, the interest-rate forecast is not part of the contract and is chosen by the central banker after the contract is signed. Second, $\widehat{\mathrm{FGC}}(b)$ allows the construction of analytically tractable, longer-term

\footnotetext{
${ }^{12}$ Renewable short-term contracts are attractive as they can reap most — or even all-possible welfare gains from Forward Guidance Contracts for small and moderate negative natural real interest-rate shocks. They constrain the central bank as little as possible and thus involve the lowest risk in case of unforeseen events.

${ }^{13}$ Details on this comparison are available on request.
} 


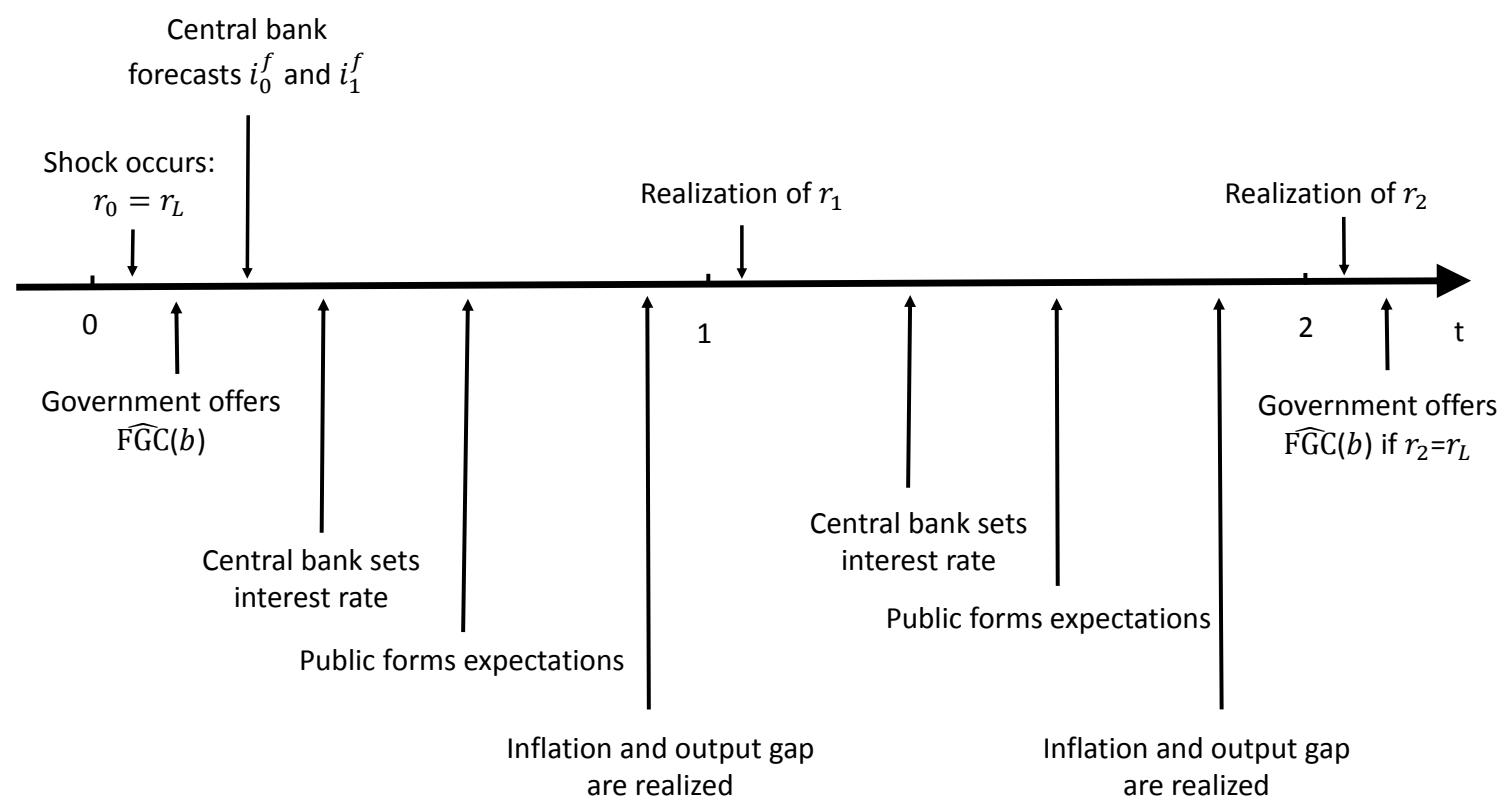

Figure 11: The sequence of events.

contracts that might be needed when the natural real interest-rate shock is extremely severe. We focus on a situation in which a negative shock to the natural real interest rate happens at the beginning of period 0 and the $\widehat{\mathrm{FGC}}(b)$ is signed immediately. We assume for the moment that the interest-rate forecast by the central bank is zero, i.e. $i_{t}^{f}=i_{t+1}^{f}=0$. We will later argue that this is indeed the optimal choice.

The detailed sequence of events is shown in Figure 11. In period 0, after the realization of $r_{L}$, the government signs an $\widehat{\mathrm{FGC}}(b)$ that makes the central banker's remuneration contingent on the precision of his forecast. Then the central banker forecasts interest rates in periods 0 and 1 . After that, the interest rate in period $0, i_{L 0}^{C}$, is set, and the realized inflation and output gap are $\pi_{L 0}^{C}$ and $x_{L 0}^{C}$.

In period $t=1$, the central banker sets $i_{H}^{C}$ if the economy has recovered and the corresponding inflation and output gap are $\pi_{H}^{C}$ and $x_{H}^{C}$. If the economy is still in a downturn, the central banker sets $i_{L 1}^{C}$, and the corresponding inflation and output gap are $\pi_{L 1}^{C}$ and $x_{L 1}^{C}$.

In period 2, the economy has either recovered and the central bank chooses the discretionary solution leading to zero inflation and zero output gap, or the natural real 
interest rate is still negative. In the latter case, the $\widehat{\mathrm{FGC}}(b)$ is re-signed and thus the central banker continues to select interest rates under Forward Guidance Contracts. ${ }^{14}$ As in Section 4, we derive the economic outcomes in periods 0 and 1.

$$
\begin{aligned}
& \pi_{L 0}^{C}=A_{0} f(b)+\pi_{L}^{D}, \\
& x_{L 0}^{C}=B_{0} f(b)+x_{L}^{D}, \\
& \pi_{L 1}^{C}=A_{1} f(b)+\pi_{L}^{D}, \\
& x_{L 1}^{C}=B_{1} f(b)+x_{L}^{D},
\end{aligned}
$$

where $A_{0}, A_{1}, B_{0}$, and $B_{1}$ are given in Appendix G.

The expected discounted intertemporal social loss is

$$
V_{L A}(C)=\frac{l_{L 0}^{C}+\beta\left[(1-\delta) l_{H}^{C}+\delta l_{L 1}^{C}\right]}{1-\beta^{2} \delta^{2}},
$$

where $l_{L 0}^{C}=0.5\left[\left(\pi_{L 0}^{C}\right)^{2}+\lambda\left(x_{L 0}^{C}\right)^{2}\right], l_{L 1}^{C}=0.5\left[\left(\pi_{L 1}^{C}\right)^{2}+\lambda\left(x_{L 1}^{C}\right)^{2}\right]$, and $l_{H}^{C}=0.5\left[\left(\pi_{H}^{C}\right)^{2}+\right.$ $\left.\lambda\left(x_{H}^{C}\right)^{2}\right]$.

\subsection{Optimal two-period contracts}

We next establish that the zero interest rate is still a binding constraint when $\widehat{\mathrm{FGC}}(b)$ is used. ${ }^{15}$

\section{Proposition 4}

1. There exists a threshold value $\hat{r}_{L A}<0$ such that the central bank will set $i_{L 0}^{C}=$ $i_{L 1}^{C}=0$ for any value of $b$ in an $\widehat{F G C}(b)$ if $r_{L} \leq \hat{r}_{L A} . \hat{r}_{L A}<0$ is given in Appendix $G$. ${ }^{16}$

2. For $\delta \leq 0.54$, the central bank sets $i_{L 0}^{C}=i_{L 1}^{C}=0$ under an optimal $\widehat{F G C}(b)$ for any $r_{L}<0$.

\footnotetext{
${ }^{14}$ In this section, we only explore the $\widehat{\mathrm{FGC}}(b)$ when the government commits to contracting. A similar exercise as in Subsection 4.2 can also be performed for this type of contract.

${ }^{15}$ The proof is available upon request.

${ }^{16}$ For small values of $\delta, \hat{r}_{L A}$ is small (e.g. $\hat{r}_{L A}=-0.029$ for $\delta=0.1$ ). For large feasible values of $\delta$, $\hat{r}_{L A}$ becomes larger (e.g. $\hat{r}_{L A}=-0.009$ for $\delta=0.5$ ).
} 
The intuition for Proposition 4 is straightforward. If the natural real interest-rate shock is sufficiently severe, the zero bound will bind for any $\widehat{\mathrm{FGC}}(b)$. No boom or inflation that can be generated by an $\widehat{\mathrm{FGC}}(b)$ after the shock has died out will suffice to lift the economy in the downturn to the level at which the central bank will optimally start to move away from the zero interest rate. By contrast, if the natural real interest-rate shock is moderate or small, optimal levels of $b$ are set at a sufficiently low level, such that the induced boom and inflation after the return to normal times do not cause the central bank to start moderating the economy in the downturn already. Too high values of $b$ would cause inefficiently large booms and inflation.

Finally, we derive the optimal value of $b$ in $\widehat{\mathrm{FGC}}(b)$.

\section{Proposition 5}

There exists a unique optimal $\widehat{F G C}(b)$ characterized by

$$
b=\left\{\begin{array}{ll}
\frac{\lambda+\kappa^{2}}{\sigma^{2}} \frac{r_{L}}{r_{L A}^{c}-r_{L}}, & \text { if } r_{L} \in\left(r_{L A}^{c}, 0\right) \\
\infty, & \text { if } r_{L} \leq r_{L A}^{c}
\end{array},\right.
$$

where $r_{L A}^{c}<0$ is a critical value of the natural real interest-rate shock given in Appendix $G .17$

Proposition 5 shows that it is optimal to use $\widehat{\mathrm{FGC}}(b)$ with small values of $b$ if the shock is small and large values if the shock is large. ${ }^{18}$

\subsection{Longer-term contracts}

We have limited ourselves to simple renewable Forward Guidance Contracts. In certain circumstances - when negative natural real interest-rate shocks are severe and recovery probability is low - one could employ renewable Forward Guidance Contracts with longer durations. While those contracts can yield even lower social losses in such circumstances, ${ }^{19}$ they also constrain the central bank for a long time and may thus be problematic, as unforeseen events requiring greater flexibility may occur in the interim.

\footnotetext{
${ }^{17}$ Again, for small values of $\delta, r_{L A}^{c}$ is small (e.g. $r_{L A}^{c}=-0.037$ for $\delta=0.1$ ). For large feasible values of $\delta, r_{L A}^{c}$ becomes larger (e.g. $r_{L A}^{c}=-0.009$ for $\delta=0.5$ ).

${ }^{18}$ We have assumed that the central bank makes zero interest-rate forecasts in downturns. However, given the choices of $b$ described in Proposition 5 making positive interest-rate forecasts in downturns would only add to losses for central bankers, since $i_{L 0}^{C}=i_{L 1}^{C}=0$ is optimal. In turn, by the same logic as in Proposition 4, setting $b$ at levels that would induce positive interest-rate forecasts cannot be optimal.

${ }^{19}$ Examples of such longer-term Forward Guidance Contracts are available upon request.
} 


\section{Discussion and conclusion}

Forward guidance aims at influencing the public's expectations, an objective that has a long tradition in monetary policy. Today the reliance on forward guidance has become a central aspect of monetary policy, often associated with the belief that forward guidance can provide a stimulus when economies are mired in longer downturns. We have explored a simple contractual tool that makes forward guidance more effective when the economy is at the zero bound.

Such Forward Guidance Contracts strike a balance between Odyssian policy commitments and the need to react to new developments. We have confined ourselves to very simple contracts, written either after a downturn or in normal times. Numerous extensions of our research could be pursued. For instance, one could take into account the fact that it takes time to learn the magnitude of the shock, so the government necessarily has to sign such contracts under a veil of ignorance, which, in turn, may call for moderate intensity of incentives.

Also, one could allow for more complex contracts such as State-contingent Forward Guidance Contracts. In such contracts, the central bankers' remuneration loss, which occurs if they deviate from the forecasts, would itself depend on macroeconomic variables such as the output gap. While such contracts could be investigated, the corresponding macroeconomic variables are difficult to verify. Thus their usability for complex Forward Guidance Contracts appears to have little potential over and above the simple contracts examined in this paper. 


\section{A Proof of Lemma 1}

In this appendix we examine the circumstances under which our previous assumption holds that the central bank will select an interest rate of zero in a downturn. For this purpose, we use (1) and (2) to replace $\pi_{t}$ and $x_{t}$ in the central bank's instantaneous loss function in period $t$ in the presence of a contract. The derivative of the resulting expression with respect to $i_{t}$ has to be weakly positive at $i_{L}^{C}=0$. Otherwise, it would be profitable to raise interest rates. Formally, this condition can be stated as

$$
\kappa \pi_{L}^{C}+\lambda x_{L}^{C} \leq 0
$$

As a next step, we evaluate $(34)$ at $\pi_{L}^{C}$ and $x_{L}^{C}$, where the latter two variables are specified in (15) and (16):

$$
\kappa\left[A f(b)+\pi_{L}^{D}\right]+\lambda\left[B f(b)+x_{L}^{D}\right] \leq 0 .
$$

Solving for $f(b)$ yields

$$
f(b) \leq-\frac{\kappa \pi_{L}^{D}+\lambda x_{L}^{D}}{\kappa A+\lambda B}=\frac{\kappa^{2}+\lambda(1-\beta \delta)}{\kappa(\kappa A+\lambda B)}\left|\pi_{L}^{D}\right| .
$$

\section{B Proof of Lemma 2}

To prove the lemma, we proceed in several steps. First, we determine the value of $b$ that minimizes the social losses represented by (24), assuming that the resulting value of $b$ satisfies (19), i.e. is small enough to ensure that the zero lower bound is binding in the downturn. Second, we show that, for this value of $b,(19)$ is actually satisfied. Third, we examine optimal central bank policy if condition $(19)$ fails to hold, i.e. in the case where $b$ is such that the zero lower bound is not binding. Fourth, we show that the government would never find it optimal to select such a value for $b$. 
Step \#1 Inserting (20) and (21) into (24) and computing the derivative with respect to $b$ reveals that this derivative is proportional to $f(b)-f^{*}$, where $f^{*}$ has been defined in 25 . We note that $f^{*}$ is positive because $\pi_{L}^{D}<0, x_{L}^{D}<0, A>0$, and $B>0$.

Recall that $f(b)$ is a strictly monotonically increasing function with $f(0)=0$. Hence for $\lim _{b \rightarrow \infty} f(b)=r_{H} / \sigma>f^{*}$, there is a unique value of $b, b^{*}$, that satisfies $f(b)=f^{*}$. This value minimizes expected social losses. By contrast, for $\lim _{b \rightarrow \infty} f(b)=r_{H} / \sigma \leq f^{*}$, social losses are a strictly monotonically decreasing function of $b \forall b \geq 0$. Loosely speaking, the optimal value of $b$ is infinitely high in this case. For the remainder of the proof we focus on the case where values of $b$ exist for which the zero lower bound would not bind in equilibrium under optimal central bank policy, i.e. we focus on $\lim _{b \rightarrow \infty} f(b)=r_{H} / \sigma>f^{*}$.

Step \#2 It is unclear as yet whether for the value of $b, b^{*}$, identified in the previous step, the zero lower bound is actually binding in equilibrium. To show this, we prove that with respect to $i_{t}$, the derivative of the central bank's loss function, with the Phillips Curve and the IS Curve used to substitute for inflation and output, is weakly positive at $i_{t}=0$ in a downturn. Formally, this condition can be stated as

$$
\left.\frac{\partial l_{t}^{C B}}{\partial i_{t}}\right|_{i_{L}^{C}=0} \geq 0
$$

Since

$$
l_{t}^{C B}=l_{L}^{C B}=\frac{1}{2}\left[\left(\pi_{L}^{C}\right)^{2}+\lambda\left(x_{L}^{C}\right)^{2}\right]+\frac{1}{2} b i_{t}^{2}
$$

with $i_{t}=i_{L}^{C}$ and

$$
\frac{\partial l_{t}^{C B}}{\partial i_{t}}=\pi_{t} \frac{\partial \pi_{t}}{\partial i_{t}}+\lambda x_{t} \frac{\partial x_{t}}{\partial i_{t}}+b i_{t}=\pi_{L}^{C}\left(-\frac{\kappa}{\sigma}\right)+\lambda x_{L}^{C}\left(-\frac{1}{\sigma}\right)+b i_{L}^{C},
$$

35) can be rewritten as

$$
\kappa \pi_{L}^{C}+\lambda x_{L}^{C} \leq 0
$$

Using $\pi_{L}^{C}=A f\left(b^{*}\right)+\pi_{L}^{D}$ and $x_{L}^{C}=B f\left(b^{*}\right)+x_{L}^{D}$, replacing $f\left(b^{*}\right)$ by $f^{*}$, and using the definition of $f^{*}$ in $(25)$, it is straightforward, though tedious, to show that (36) is satisfied for $b=b^{*}$. 
Step \#3 So far, we have determined the optimal choice of $b$ from all values for which the zero lower bound binds in equilibrium. However, it is conceivable that the government would select a value of $b$ such that this would not be the case, i.e. a value for which (19) is violated. Hence, we consider the equilibrium for this range of $b$ in this step. In the fourth step, we demonstrate that the government would never select such a value for $b^{*}$.

If the zero lower bound does not bind, the following first-order condition holds in state $L$ under a Forward Guidance Contract, as can easily be shown:

$$
\kappa \hat{\pi}_{L}^{C}+\lambda \hat{x}_{L}^{C}-b \sigma i_{L}^{C}=0
$$

The Phillips Curve (2), $\hat{\pi}_{L}^{C}=\beta\left(\delta \hat{\pi}_{L}^{C}+(1-\delta) \pi_{H}^{C}\right)+\kappa \hat{x}_{L}^{C}$, the IS Curve (1), $\hat{x}_{L}^{C}=$ $-\sigma^{-1}\left[i_{L}^{C}-\left(\delta \hat{\pi}_{L}^{C}+(1-\delta) \pi_{H}^{C}\right)-r_{L}\right]+\left(\delta \hat{x}_{L}^{C}+(1-\delta) x_{H}^{C}\right),(9)$, 10), and 37) can be used to compute

$$
\begin{aligned}
& \hat{\pi}_{L}^{C}=z(b) \frac{\kappa(1-\delta)(\beta \lambda+b \sigma(\kappa+\sigma(1+\beta(1-\delta))))}{\kappa^{2}+\lambda+b \sigma^{2}} r_{H}+z(b) \kappa r_{L}, \\
& \hat{x}_{L}^{C}=z(b) \frac{(1-\delta)\left(-\beta \kappa^{2}+b \sigma(\kappa+\sigma(1-\beta \delta))\right)}{\kappa^{2}+\lambda+b \sigma^{2}} r_{H}+z(b)(1-\beta \delta) r_{L},
\end{aligned}
$$

where

$$
z(b):=\frac{b \sigma}{\left.\kappa^{2}+\lambda(1-\beta \delta)+b \sigma(\sigma(1-\delta)(1-\beta \delta))-\delta \kappa\right)} .
$$

We observe that $z(b)$ is a monotonically increasing function of $b$ (recall our previous assumption $\sigma(1-\delta)(1-\beta \delta)-\delta \kappa>0)$.

Step \#4 With the help of (38) and (39), per-period losses in a downturn, under the assumption that $b$ is sufficiently high for the zero lower bound not to be binding $(b \geq \hat{b})$, can be written as

$$
\begin{aligned}
\hat{l}_{L}^{C}=\left(\hat{\pi}_{L}^{C}\right)^{2} & +\lambda\left(\hat{x}_{L}^{C}\right)^{2} \\
=z(b)^{2}[ & \left(\frac{\kappa(1-\delta)(\beta \lambda+b \sigma(\kappa+\sigma(1+\beta(1-\delta))))}{\kappa^{2}+\lambda+b \sigma^{2}} r_{H}+\kappa r_{L}\right)^{2} \\
& \left.+\lambda\left(\frac{(1-\delta)\left(-\beta \kappa^{2}+b \sigma(\kappa+\sigma(1-\beta \delta))\right)}{\kappa^{2}+\lambda+b \sigma^{2}} r_{H}+(1-\beta \delta) r_{L}\right)^{2}\right] .
\end{aligned}
$$


Using $f(b)=\frac{b \sigma}{\lambda+\kappa^{2}+b \sigma^{2}} r_{H}$ and $\frac{1}{\lambda+\kappa^{2}+b \sigma^{2}} r_{H}=\frac{r_{H}-\sigma f(b)}{\kappa^{2}+\lambda}($ see 12 ), we can restate 41, as follows:

$$
\begin{aligned}
\hat{l}_{L}^{C}= & z(b)^{2}\left[\left(\kappa(1-\delta)\left(\frac{r_{H}-\sigma f(b)}{\kappa^{2}+\lambda} \beta \lambda+f(b)(\kappa+\sigma(1+\beta(1-\delta)))\right)+\kappa r_{L}\right)^{2}\right. \\
& \left.+\lambda\left((1-\delta)\left(-\frac{r_{H}-\sigma f(b)}{\kappa^{2}+\lambda} \beta \kappa^{2}+f(b)(\kappa+\sigma(1-\beta \delta))\right)+(1-\beta \delta) r_{L}\right)^{2}\right] .
\end{aligned}
$$

We will now explain that 42 is a monotonically increasing function of $b$ for $b \geq \hat{b}$, where $\hat{b}$ is implicitly defined by 19 . This follows from two observations. First, we have already noted that $z(b)$ monotonically increases with $b \forall b \geq 0$. Second, the term in brackets in 42 is a quadratic function of $f(b)$. It is straightforward, though tedious, to show that the minimum of this term, interpreted as a function of $f(b)$, is at $f(b)=f(\hat{b})$, where $f(\hat{b})$ is given by the right-hand side of 19 . Hence 42 monotonically increases with $b$ for $b \geq \hat{b}$.

Because at $b=\hat{b}, l_{L}^{C}=\hat{l}_{L}^{C}$ holds ${ }^{20}$ and $l_{L}^{C}$, evaluated at $\hat{b}$, has to be larger than at $b=b^{*}$ as $b^{*}$ is the value of $b$ minimizing $l_{L}^{C}$, we can conclude that the government would not choose a value of $b$ with $b \geq \hat{b}$.

\section{Proof of Lemma 3}

\section{C.1 Preliminary steps}

We need to define the strategy of the government in the candidate equilibrium precisely. We assume that the government will always sign a new contract for the next period in state $L$, independently of whether a contract has been signed for the current period. Moreover, we consider the case where the government never signs a contract for the next period if the economy is in state $H$, irrespective of whether a contract exists for the current period.

\footnotetext{
${ }^{20} \mathrm{It}$ is somewhat tedious but straightforward to verify that, for $b=\hat{b}, \pi_{L}^{C}=\hat{\pi}_{L}^{C}=$ $-\frac{\lambda \beta \kappa r_{L}}{\kappa^{3}+\sigma(1+\beta(1-\delta)) \kappa^{2}+\lambda \kappa+\sigma \lambda(1-\beta \delta)}$ and $x_{L}^{C}=\hat{x}_{L}^{C}=\frac{\beta \kappa^{2} r_{L}}{\kappa^{3}+\sigma(1+\beta(1-\delta)) \kappa^{2}+\lambda \kappa+\sigma \lambda(1-\beta \delta)}$, which implies the continuity of social losses, interpreted as a function of $b$, at $b=\hat{b}$.
} 
Next we examine whether, for the government, profitable deviations exist in a particular period, when the government takes its own future behavior, the behaviors of the central bank and of the private sector as given. There are four potential deviations. First, in a situation where a contract is present in the current period and where the current economic state is $L$, the government chooses not to sign a contract for the next period. Second, the government refuses to offer a contract in state $L$, given that no contract is present in the current period. Third, in state $H$ the government offers a contract for the next period if a contract is active in the current period. Fourth, in state $H$ without a contract in the current period, the government introduces a contract for the next period.

It is comparably straightforward to show that the third and fourth deviation cannot be profitable. Showing that the other deviations are undesirable for the government is more cumbersome and requires a few preliminary steps and some additional notation.

Let $V_{s}(C)$ be the discounted future social losses for optimal central-bank and privatesector behaviors, given the current state $s \in\{L, H\}$, the fact that the government pursues the strategy described above, and that a contract has been signed for the current period. $V_{s}(N)$ is the analogous expression for the case where no contract is present in the current period. Moreover, let $l_{s}^{X Y}$ with $s \in\{H, L\}$ and $X, Y \in\{C, N\}$ be the per-period losses in state $s$ if currently there is a contract $(X=C)$ or no contract $(X=N)$ and if in the current period a contract is signed for the next period $(Y=C)$ or $\operatorname{not}(Y=N)$.

We obtain the following equations:

$$
\begin{aligned}
V_{L}(C) & =l_{L}^{C C}+\beta\left(\delta V_{L}(C)+(1-\delta) V_{H}(C)\right), \\
V_{H}(C) & =l_{H}^{C N}+\beta V_{H}(N), \\
V_{L}(N) & =l_{L}^{N C}+\beta\left(\delta V_{L}(C)+(1-\delta) V_{H}(C)\right), \\
V_{H}(N) & =l_{H}^{N N}+\beta V_{H}(N) .
\end{aligned}
$$

We note that $l_{H}^{N N}=0, l_{L}^{C N}=l_{L}^{N N}$, and $l_{L}^{C C}=l_{L}^{N C}$, where the latter two conditions follow from the observation that the zero lower bound always binds in state $s=L$, irrespective of whether a contract was signed in the previous period. This observation will be shown formally later. 
As a result, we obtain

$$
\begin{aligned}
V_{L}(C) & =\frac{1}{1-\beta \delta} l_{L}^{C C}+\frac{\beta(1-\delta)}{1-\beta \delta} l_{H}^{C N}, \\
V_{H}(C) & =l_{H}^{C N}, \\
V_{L}(N) & =\frac{1}{1-\beta \delta} l_{L}^{C C}+\frac{\beta(1-\delta)}{1-\beta \delta} l_{H}^{C N}, \\
V_{H}(N) & =0 .
\end{aligned}
$$

\section{C.2 Deviation in state $L$ when a contract was signed in the previous period}

We are now in a position to specify the condition that ensures that the government does not find it optimal to refuse to offer a contract for the next period, given that the current state is $L$ and that a contract was signed in the previous period:

$$
l_{L}^{C N}+\beta\left(\delta V_{L}(N)+(1-\delta) V_{H}(N)\right) \geq V_{L}(C) .
$$

The right-hand side of the inequality states the losses incurred if the government does not deviate. The expression on the left-hand side represents social losses if the government does not offer a contract in the period under consideration but pursues its equilibrium strategy in all future periods. With the help of (47)-(50), (51) can be simplified to

$$
l_{L}^{C N} \geq l_{L}^{C C}+\beta(1-\delta) l_{H}^{C N}
$$

This condition will be analyzed in more detail later.

\section{C.3 Deviation in state $L$ when a contract was not signed in the previous period}

In state $L$, the government will find it optimal to offer a contract for the next period, provided that no contract was signed in the previous period, if

$$
l_{L}^{N N}+\beta\left(\delta V_{L}(N)+(1-\delta) V_{H}(N)\right) \geq V_{L}(N) .
$$

Because $l_{L}^{N N}=l_{L}^{C N}$ and $V_{L}(N)=V_{L}(C)$, this condition is equivalent to (51) and thus to $(52)$. 


\section{C.4 Evaluating condition 52 )}

To evaluate condition (52), we have to determine $l_{L}^{C N}, l_{L}^{C C}$, and $l_{H}^{C N}$. For this purpose, we observe that $l_{L}^{C C}$ and $l_{H}^{C N}$ are per-period losses that also occur in the candidate equilibrium. Hence, we obtain

$$
\begin{aligned}
& l_{L}^{C C}=\left(\pi_{L}^{C}\right)^{2}+\lambda\left(x_{L}^{C}\right)^{2}, \\
& l_{H}^{C N}=\left(\pi_{H}^{C}\right)^{2}+\lambda\left(x_{H}^{C}\right)^{2} .
\end{aligned}
$$

To determine $l_{L}^{C N}$, we have to compute inflation and the output gap, $\pi_{L}^{C N}$ and $x_{L}^{C N}$, for the case where the government does not offer a contract in state $L$ for the next period but reverts to its putative equilibrium strategy in all future periods, i.e. it will offer a contract in state $L$ and no contract in state $H$. In such a situation, expectations of inflation and the output gap are

$$
\begin{aligned}
& \mathbb{E}_{t}\left[\pi_{t+1}\right]=\delta \pi_{L}^{N C}+(1-\delta) \pi_{H}^{N N}=\delta \pi_{L}^{C}, \\
& \mathbb{E}_{t}\left[x_{t+1}\right]=\delta x_{L}^{N C}+(1-\delta) x_{H}^{N N}=\delta x_{L}^{C} .
\end{aligned}
$$

It is tedious but straightforward to show that inserting these two expressions into (1) and (2), evaluated at $i_{t}=0$, yields

$$
\begin{aligned}
\pi_{L}^{C N} & =P f(b)+\pi_{L}^{D}, \\
x_{L}^{C N} & =Q f(b)+x_{L}^{D},
\end{aligned}
$$

where $\pi_{L}^{D}, x_{L}^{D}$, and $f(b)$ have been introduced in (5), (12), and (4) respectively, and $P$ and $Q$ are given by

$$
\begin{aligned}
P & :=\delta\left[\left(\frac{\kappa}{\sigma}+\beta\right) A+\kappa B\right], \\
Q & :=\delta\left(\frac{A}{\sigma}+B\right) .
\end{aligned}
$$

Recall that $A$ and $B$ have been defined in (17) and (18).

\section{C.5 Verifying that the zero lower bound binds for the devia- tions}

It remains to be verified that the zero lower bound is also binding for the deviations analyzed above if $(19)$ is satisfied, which ensures that it is binding in state $L$ in equilibrium when a contract is present in the current period. We note that this is the case 
for

$$
\kappa \pi_{L}^{C N}+\lambda x_{L}^{C N} \leq 0
$$

Using (19), 58), 59, and $x_{L}^{D}=\frac{1-\beta \delta}{\kappa} \pi_{L}^{D}$, which follows from (4) and (5), and rearranging results in the condition yields

$$
\frac{\kappa P+\lambda Q}{\kappa A+\lambda B} \leq 1
$$

It is straightforward to show $A-P=\frac{\kappa(1-\delta)(\kappa+\sigma(1+\beta))}{\sigma}>0$ and $B-Q=\frac{(1-\delta)(\kappa+\sigma)}{\sigma}>0$, which, together with $P>0$ and $Q>0$, implies $(63)$.

\section{C.6 Simplifying condition $(52)$}

Finally, we simplify condition (52) to identify the set of parameter values for which no profitable deviation for the government exists. The condition can be written as

$$
\begin{gathered}
0 \leq\left(\pi_{L}^{N N}\right)^{2}+\lambda\left(x_{L}^{N N}\right)^{2}-\left(\pi_{L}^{C}\right)^{2}-\lambda\left(x_{L}^{C}\right)^{2}-\beta(1-\delta)\left(\pi_{H}^{C}\right)^{2}-\beta(1-\delta) \lambda\left(x_{H}^{C}\right)^{2} \\
=-\left(A^{2}-P^{2}+\lambda B^{2}-\lambda Q^{2}+\beta(1-\delta)\left(\kappa^{2}+\lambda\right)\right)(f(b))^{2} \\
-2\left(A-P+\lambda(B-Q) \frac{1-\beta \delta}{\kappa}\right) f(b) \pi_{L}^{D} .
\end{gathered}
$$

As $\pi_{L}^{D}<0, A^{2}-P^{2}+\lambda B^{2}-\lambda Q^{2}+\beta(1-\delta)\left(\kappa^{2}+\lambda\right)>0$, and $\left(A-P+\lambda(B-Q) \frac{1-\beta \delta}{\kappa}\right)>0$ (due to $A>P$ and $B>Q$ ), we can conclude that this expression is weakly positive for all values of $f(b)$ with $f(b) \geq 0$ that are smaller than or equal to $2 \tilde{f}$, where

$$
\tilde{f}:=\frac{A-P+\lambda(B-Q) \frac{1-\beta \delta}{\kappa}}{A^{2}-P^{2}+\lambda B^{2}-\lambda Q^{2}+\beta(1-\delta)\left(\kappa^{2}+\lambda\right)}\left|\pi_{L}^{D}\right| .
$$

Hence no profitable deviation exists for the government if $f^{*} \leq 2 \tilde{f}$, where

$$
f^{*}=\frac{A+\lambda B \frac{1-\beta \delta}{\kappa}}{A^{2}+\lambda B^{2}+\beta(1-\delta)\left(\lambda+\kappa^{2}\right)}\left|\pi_{L}^{D}\right| .
$$




\section{Proof of Proposition 2}

Suppose that the value of $b$ corresponded to the optimal value $b^{* *}$ for the realization $r_{L}=\bar{r}_{L}$. Clearly, for this particular realization of $r_{L}$, social welfare would be higher than in the benchmark case. In the following we show that this value of $b$ also leads to welfare improvements for all other realizations of $r_{L}$. For this purpose, we note that $b^{* *}$ is a monotonically increasing function of $\left|r_{L}\right|$, as both $\tilde{f}$ and $f^{*}$ are increasing linear functions of $\left|\pi_{L}^{D}\right|$, which, in turn, monotonically increases with $\left|r_{L}\right|$. As social losses interpreted as a function of $f(b)$ are monotonically decreasing for all $f(b) \leq f^{*}$, we can conclude that the value of $b$ optimal for $\bar{r}_{L}$ would also increase welfare for all other realizations of $r_{L}$.

\section{E Proof of Lemma 4}

With a given $\tilde{b}$, inserting $(38)$ and $(39)$ into 37 yields

$$
i_{L}^{C}(\tilde{b})=\frac{(\kappa A+\lambda B)[\sigma(1-\delta)(1-\beta \delta)-\delta \kappa] f(\tilde{b})+\left[\kappa^{2}+\lambda(1-\beta \delta)\right] r_{L}}{b \sigma[\sigma(1-\delta)(1-\beta \delta)-\delta \kappa]+\kappa^{2}+\lambda(1-\beta \delta)},
$$

where $f(\tilde{b})$ is given ${ }^{21}$ in 25 in Lemma 2

Equation (66) implies that $i_{L}^{C}>0$ if and only if $r_{L}>a \tilde{r}_{L}$, where

$$
a:=\frac{(\kappa A+\lambda B)[\kappa A+\lambda B(1-\beta \delta)]}{\left[\kappa^{2}+\lambda(1-\beta \delta)\right]\left[A^{2}+\lambda B^{2}+\beta(1-\delta)\left(\lambda+\kappa^{2}\right)\right]} .
$$

Therefore, the zero lower bound is binding when $r_{L} \leq a \tilde{r}_{L}$.

We next prove that it is socially desirable to offer the $\operatorname{FGC}(\tilde{b})$ when $r_{L} \leq a \tilde{r}_{L}$.

We can write the discounted social loss under discretion as in (24):

$$
V_{L}(D)=\frac{1}{1-\beta \delta} l_{L}^{D}
$$

where $l_{L}^{D}=0.5\left[\left(\pi_{L}^{D}\right)^{2}+\lambda\left(x_{L}^{D}\right)^{2}\right]$.

\footnotetext{
${ }^{21}$ Recall that $\tilde{b}$ is the optimal value of $b$ when $r_{L}=\tilde{r}_{L}$.
} 
The government would offer the contract when $r_{L} \leq a \tilde{r}_{L}$ if and only if the discounted social loss with $\mathrm{FGC}(\tilde{b})$ were lower than the one in the benchmark case:

$$
V_{L}(C)<V_{L}(D)
$$

Solving 69 yields

$$
r_{L}<0.5 \tilde{r}_{L}
$$

In our calibration ${ }^{22}, a=0.95>0.5$. Therefore, for all $r_{L} \leq a \tilde{r}_{L}, 6$ is satisfied and it is socially desirable to offer the Forward Guidance Contract in these circumstances.

\section{F Proof of Proposition 3}

We have derived (15) and (16), assuming the zero lower bound is binding. In a similar vein, we now derive the inflation and output gap in downturn with a given $\mathrm{FGC}(\tilde{b})$, without assuming that the zero lower bound is binding. We obtain

$$
\pi_{L}^{C}=A f(\tilde{b})+\frac{\kappa}{\sigma(1-\delta)(1-\beta \delta)-\delta \kappa}\left(r_{L}-i_{L}^{C}\right)
$$

and

$$
x_{L}^{C}=B f(\tilde{b})+\frac{1-\beta \delta}{\sigma(1-\delta)(1-\beta \delta)-\delta \kappa}\left(r_{L}-i_{L}^{C}\right)
$$

The government would offer the Forward Guidance Contract if and only if (69) applied.

Inserting 66), (70), and (71) into 69) yields

$$
r_{L}<\tilde{r}_{L}^{c}
$$

where

$$
\begin{gathered}
\tilde{r}_{L}^{c}=\frac{a_{1} a_{2}+\lambda a_{3} a_{4}-\sqrt{\left(a_{1} a_{2}+\lambda a_{3} a_{4}\right)^{2}+\left(a_{5}-a_{1}^{2}-\lambda a_{3}^{2}\right)\left[a_{2}^{2}+\lambda a_{4}^{2}+\beta(1-\delta)\left(\lambda+\kappa^{2}\right)\right]}}{a_{5}-a_{1}^{2}-\lambda a_{3}^{2}} f(\tilde{b}), \\
a_{1}:=\frac{\kappa \sigma \tilde{b}}{\sigma[\sigma(1-\delta)(1-\beta \delta)-\delta \kappa] \tilde{b}+\kappa^{2}+\lambda(1-\beta \delta)},
\end{gathered}
$$

\footnotetext{
${ }^{22}$ Numerical result shows that for all $\delta$ that satisfy Assumption $1, a>0.5$ is fulfilled.
} 


$$
\begin{gathered}
a_{2}:=\frac{\sigma A[\sigma(1-\delta)(1-\beta \delta)-\delta \kappa] \tilde{b}+\lambda(1-\beta \delta) A-\lambda \kappa B}{\sigma[\sigma(1-\delta)(1-\beta \delta)-\delta \kappa] \tilde{b}+\kappa^{2}+\lambda(1-\beta \delta)}, \\
a_{3}:=\frac{(1-\beta \delta) \sigma \tilde{b}}{\sigma[\sigma(1-\delta)(1-\beta \delta)-\delta \kappa] \tilde{b}+\kappa^{2}+\lambda(1-\beta \delta)}, \\
a_{4}:=\frac{\sigma B[\sigma(1-\delta)(1-\beta \delta)-\delta \kappa] \tilde{b}+\kappa^{2} B-\kappa(1-\beta \delta) A}{\sigma[\sigma(1-\delta)(1-\beta \delta)-\delta \kappa] \tilde{b}+\kappa^{2}+\lambda(1-\beta \delta)}, \\
a_{5}:=\frac{\kappa^{2}+\lambda(1-\beta \delta)^{2}}{[\sigma(1-\delta)(1-\beta \delta)-\delta \kappa]^{2}} .
\end{gathered}
$$

\section{G Parameters for Section 5}

$$
\begin{aligned}
A_{0} & :=\frac{\kappa \sigma(\kappa+\sigma+\sigma \beta)(1-\delta)}{[\sigma(1-\delta)(1-\beta \delta)-\delta \kappa][\sigma(1+\delta)(1+\beta \delta)+\delta \kappa]} \\
B_{0} & :=\frac{\sigma\left(\kappa+\sigma-\sigma \beta^{2} \delta^{2}\right)(1-\delta)}{[\sigma(1-\delta)(1-\beta \delta)-\delta \kappa][\sigma(1+\delta)(1+\beta \delta)+\delta \kappa]} \\
A_{1} & :=\frac{\kappa \delta(1-\delta)\left[(\kappa+\sigma)^{2}+\sigma^{2} \beta+2 \kappa \sigma \beta+\sigma^{2} \beta^{2}\left(1-\delta^{2}\right)\right]}{[\sigma(1-\delta)(1-\beta \delta)-\delta \kappa][\sigma(1+\delta)(1+\beta \delta)+\delta \kappa]} \\
B_{1} & :=\frac{\delta(1-\delta)\left[(\kappa+\sigma)^{2}+\kappa \sigma \beta-\sigma^{2} \beta^{2} \delta^{2}\right]}{[\sigma(1-\delta)(1-\beta \delta)-\delta \kappa][\sigma(1+\delta)(1+\beta \delta)+\delta \kappa]} \\
\hat{r}_{L A} & :=-\frac{(1-\delta)\left[\kappa^{2}(\sigma \beta+\kappa+\sigma)+\lambda\left(\kappa+\sigma-\sigma \beta^{2} \delta^{2}\right)\right]}{\left[\kappa^{2}+\lambda(1-\beta \delta)\right][\sigma(1+\delta)(1+\beta \delta)+\delta \kappa]} r_{H} \\
r_{L A}^{c} & :=-\frac{\Delta \Delta_{2}}{\sigma \Delta_{1}[\sigma(1+\delta)(1+\beta \delta)+\delta \kappa]} r_{H} \\
\Delta_{1} & :=\sigma \kappa^{2}(\sigma \beta+\kappa+\sigma)+\sigma \lambda\left(\kappa+\sigma-\sigma \beta^{2} \delta^{2}\right)(1-\beta \delta) \\
& +\beta \delta^{2} \kappa^{2}\left[(\sigma \beta+\kappa+\sigma)^{2}-\beta \sigma^{2}\left(1+\beta \delta^{2}\right)\right] \\
+ & \beta \lambda \delta^{2}(1-\beta \delta)\left[\kappa \sigma \beta+(\kappa+\sigma)^{2}-\sigma^{2} \beta^{2} \delta^{2}\right] \\
\Delta_{2} & :=\sigma^{2}(1-\delta) \kappa^{2}(\sigma \beta+\kappa+\sigma)^{2}+\sigma^{2} \lambda(1-\delta)\left(\kappa+\sigma-\sigma \beta^{2} \delta^{2}\right)^{2} \\
& +\beta \delta^{3}(1-\delta) \kappa^{2}\left[(\sigma \beta+\kappa+\sigma)^{2}-\beta \sigma^{2}\left(1+\beta \delta^{2}\right)\right]^{2} \\
+ & \beta \lambda \delta^{3}(1-\delta)\left[\kappa \sigma \beta+(\kappa+\sigma)^{2}-\sigma^{2} \beta^{2} \delta^{2}\right]^{2} \\
+ & \beta\left(\kappa^{2}+\lambda\right)[\sigma(1-\delta)(1-\beta \delta)-\delta \kappa]^{2}[\sigma(1+\delta)(1+\beta \delta)+\delta \kappa]^{2}
\end{aligned}
$$




\section{H Microfoundation of the central banker's objec- tive function}

In this section we consider only the objective function of the central bank, as the foundations of the other elements of our model are well-known from the literature (see Eggertsson (2005)). We assume, as is standard, that the economy is populated by a continuum of identical infinitely-lived households. In addition, there is an individual central banker. Hence, the central banker's individual consumption choices have no consequences for aggregate output and consumption.

We derive the central banker's intertemporal social losses with Forward Guidance Contracts. The central banker aims at achieving a high individual utility. Moreover, he is altruistic and is also interested in furthering the well-being of the other agents. More precisely, the central banker faces one of two wage schemes. If no Forward Guidance Contract is in effect, he receives a fixed wage $\bar{w} \geq 0$. By contrast, if a Forward Guidance Contract was signed, the central banker is paid according to the deviation of his actual choice of nominal interest rate from the forecast $w_{t}^{C B}=\zeta\left(\tilde{i}_{t}\right) \geq 0$, where $w_{t}^{C B}$ is the real wage paid to the central banker and $\tilde{i}_{t}=i_{t}-i_{t}^{f}$ is the deviation of the interestrate choice from the forecast made at the time when the contract is signed. We focus on functions $\zeta(\cdot)$ with a global maximum, $\bar{w}^{C B}$, at $\tilde{i}_{t}=0$, which satisfy $\zeta^{\prime}(0)=0$, $\zeta^{\prime}\left(\tilde{i}_{t}>0\right)<0$ and $\zeta^{\prime \prime}(0)<0$. Hence, the central banker faces wage reductions increasing with the size of the deviation from his earlier announcements. The central banker's wage is financed through a lump-sum tax. We note that payment to the central banker is negligible at the aggregate level, so the lump-sum tax necessary to finance his wage does not affect the households' budget constraints.

We make the extreme assumption that the central banker is excluded from trading in financial markets. The main motivation for this assumption is that the central banker should be prevented from hedging against the variations of his income. ${ }^{23}$

\footnotetext{
${ }^{23}$ This is in line with actual practices, as central bankers have to adhere to procedures for the management of their personal assets that avoid a conflict of interest (see Swiss National Bank, Bankrat (2012) and European Central Bank, Banking Supervision (2014)). With Forward Guidance Contracts, prohibiting the use of hedging instruments would be particularly important.
} 
For simplicity, we assume that the central banker is infinitely-lived and has the same individual utility from consumption and discount factor $\beta$ as the households. The central banker's utility from consumption is

$$
u\left(C_{t}^{C B}\right)=\frac{\left(C_{t}^{C B}\right)^{1-\sigma}-1}{1-\sigma}=\frac{\zeta\left(\tilde{i_{t}}\right)^{1-\sigma}-1}{1-\sigma} .
$$

We evaluate this expression in the steady state with $\tilde{i}$ equal to 0 . Thus the second-order Taylor approximation delivers

$$
u\left(C_{t}^{C B}\right) \approx \frac{\zeta(0)^{1-\sigma}-1}{1-\sigma}+\zeta(0)^{-\sigma} \zeta^{\prime}(0) \tilde{i}_{t}+\left.\frac{1}{2} \frac{\partial}{\partial \tilde{i}_{t}}\left(\zeta\left(\tilde{i}_{t}\right)^{-\sigma} \zeta^{\prime}\left(\tilde{i}_{t}\right)\right)\right|_{\tilde{i}_{t}=0} \tilde{i}_{t}^{2} .
$$

Since $\zeta^{\prime}(0)=0$, we can rewrite the approximation as

$$
u\left(C_{t}^{C B}\right) \approx \frac{\zeta(0)^{1-\sigma}-1}{1-\sigma}+\frac{1}{2} \zeta(0)^{-\sigma} \zeta^{\prime \prime}(0) \tilde{i}_{t}^{2} .
$$

The first term is constant. The constant utility term can be neglected when we compute the behavior of central bankers. However, the constant utility term and thus the fixed wage $\bar{w}^{C B}$ are important to satisfy participation constraints of central bankers. Wage $\bar{w}^{C B}$ has to be set at levels at which central bankers are at least as well off as in other occupations - e.g. being a household. We assume that $\bar{w}^{C B}$ is set at levels at which the participation constraint is fulfilled.

As mentioned earlier, the central banker is also altruistic towards households. Specifically, the overall loss of the central banker in period $t$ is

$$
\alpha l_{t}-u\left(C_{t}^{C B}\right)=\frac{\alpha}{2}\left(\pi_{t}^{2}+\lambda x_{t}^{2}-2 \frac{\zeta(0)^{1-\sigma}-1}{\alpha(1-\sigma)}-\frac{\zeta(0)^{-\sigma} \zeta^{\prime \prime}(0)}{\alpha} \tilde{i}_{t}^{2}\right),
$$

with $\alpha$ being the weight of altruism. We scale the overall loss of the central banker by $\frac{1}{\alpha}$ and deduct the constant term. The resulting loss function is denoted by $l_{t}^{C B}$ and given by

$$
l_{t}^{C B}=\frac{1}{2}\left(\pi_{t}^{2}+\lambda x_{t}^{2}-\frac{\zeta(0)^{-\sigma} \zeta^{\prime \prime}(0)}{\alpha} \tilde{i}_{t}^{2}\right) .
$$

We $\operatorname{set}^{24} b=-\frac{\zeta(0)^{-\sigma} \zeta^{\prime \prime}(0)}{\alpha}$ and obtain

$$
l_{t}^{C B}=\frac{1}{2}\left(\pi_{t}^{2}+\lambda x_{t}^{2}+b \tilde{i}_{t}^{2}\right) .
$$

We note that the sensitivity of the wage scheme with regard to the precision of forecasts, $\zeta^{\prime \prime}(0)$, enters weight $b$ of the deviation of the interest-rate forecast from actual policy choice in the loss function of the central banker.

\footnotetext{
${ }^{24}$ We note that the extreme case $b=\infty$ implies $\zeta^{\prime \prime}(0)=-\infty$.
} 


\section{References}

Beetsma, R. M. W. J. and Jensen, H. (1998). Inflation targets and contracts with uncertain central banker preferences. Journal of Money, Credit, and Banking, 30(3):384403.

Beetsma, R. M. W. J. and Jensen, H. (1999). Optimal inflation targets, "conservative" central banks, and linear inflation contracts: Comment. American Economic Review, $89(1): 342-348$.

Campbell, J. R., Evans, C. L., Fisher, J. D., and Justiniano, A. (2012). Macroeconomic effects of Federal Reserve forward guidance. Brookings Papers on Economic Activity, $44(1): 1-80$.

Campbell, J. Y. (2008). Asset Prices and Monetary Policy. University of Chicago Press, Chicago, IL.

Carlstrom, C., Fuerst, T., and Paustian, M. (2012). Inflation and output in New Keynesian models with a transient interest rate peg. Bank of England Working Paper 459.

Economist (2014). Fixing forward guidance, February 15, 2014.

Eggertsson, G. B. (2003). How to fight deflation in a liquidity trap: Committing to being irresponsible. International Monetary Fund Working Paper 03/64.

Eggertsson, G. B. (2005). Optimal monetary and fiscal policy under discretion in the New Keynesian model: A technical appendix to great expectations and the end of the depression. Federal Reserve Bank of New York Staff Reports, (235).

Eggertsson, G. B. (2006). The deflation bias and committing to being irresponsible. Journal of Money, Credit, and Banking, 38(2):283-321.

Eggertsson, G. B. and Woodford, M. (2003). The zero bound on interest rates and optimal monetary policy. Brookings Papers on Economic Activity, 34(1):139-235.

European Central Bank, Banking Supervision (2014). Code of Conduct for the Members of the Supervisory Board of the European Central Bank, 12 November 2014. 
Gersbach, H. and Hahn, V. (2011). Monetary policy inclinations. Journal of Money, Credit, and Banking, 43(8):1707-1717.

Gersbach, H. and Hahn, V. (2014). Inflation forecast contracts. Journal of Economic Dynamics and Control, 48:26 - 40.

Gurkaynak, R. S., Sack, B., and Swanson, E. T. (2005). Do actions speak louder than words? The response of asset prices to monetary policy actions and statements. International Journal of Central Banking, 1(1):55-93.

Jensen, H. (1997). Credibility of optimal monetary delegation. American Economic Review, 87(5):911-920.

Krugman, P. (1998). It's baaack: Japan's slump and the return of the liquidity trap. Brookings Papers on Economic Activity, 29(2):137-206.

Lim, W. B. and Goodhart, C. (2011). Interest rate forecasts: A pathology. International Journal of Central Banking, 7(2):135-172.

Lockwood, B. (1997). State-contingent inflation contracts and unemployment persistence. Journal of Money, Credit, and Banking, 29(3):286-299.

Mirkov, N. and Natvik, G. J. (2013). Announcements of interest rate forecasts: Do policymakers stick to them? University of St. Gallen Working Paper on Finance 1303.

Persson, T. and Tabellini, G. (1993). Designing institutions for monetary stability. Carnegie-Rochester Conference Series on Public Policy, 39(1):53-84.

Svensson, L. E. O. (1997). Optimal inflation targets, "conservative" central banks, and linear inflation contracts. American Economic Review, 87(1):98-114.

Swiss National Bank, Bankrat (2012). Reglement für private Finanzanlagen und Finanzgeschäfte von Mitgliedern der Bankleitung vom 9. März 2012 (put into force on 1 May 2012), Regulations on Private Financial Investments and Financial Transactions by Members of SNB Management 9 March 2012.

Walsh, C. E. (1995). Optimal contracts for central bankers. American Economic Review, 85(1):150-167. 
Werning, I. (2011). Managing a liquidity trap: Monetary and fiscal policy. National Bureau of Economic Research Working Paper 17344.

Woodford, M. (2012). Methods of policy accommodation at the interest-rate lower bound. Proceedings of the Economic Policy Symposium at Jackson Hole in August 2012, pages 185-288. 


\section{List of variables and notations}

Table 2: List of variables and notations (1)

\begin{tabular}{|c|c|}
\hline Variables & Description \\
\hline$\pi_{t}, x_{t}, i_{t}$ & inflation, output gap, nominal interest rate in period $t$ \\
\hline$\beta$ & households' discount factor \\
\hline$\kappa$ & coefficient in Phillips Curve \\
\hline$\sigma$ & relative risk-aversion coefficient of consumption \\
\hline$\delta$ & the probability of the economy being trapped in the downturn in each period \\
\hline$\lambda$ & relative weight of output-gap objective with respect to inflation objective \\
\hline$i_{t}^{f}$ & central banker's forecast of interest rate in period $t$ \\
\hline$b$ & intensity of incentives provided by Forward Guidance Contracts \\
\hline$s \in L, H$ & low and high states \\
\hline$r_{t}, r_{H}, r_{L}$ & natural real interest rate in period $t$, in states $\mathrm{H}$ and $\mathrm{L}$ \\
\hline$C, N$ & an active contract exists, no active contract exists \\
\hline$\pi_{s}^{D}, x_{s}^{D}, i_{s}^{D}$ & inflation, output gap, and interest rate in state $s$ in discretion \\
\hline$\pi_{s}^{C}, x_{s}^{C}, i_{s}^{C}$ & inflation, output gap, and interest rate in state $s$ with an active contract \\
\hline$\pi_{s}^{N}, x_{s}^{N}, i_{s}^{N}$ & $\begin{array}{l}\text { inflation, output gap, and interest rate in state } s \text { without active contract } \\
\pi_{s}^{N}, x_{s}^{N}, i_{s}^{N} \text { are equivalent to } \pi_{s}^{D}, x_{s}^{D}, i_{s}^{D}\end{array}$ \\
\hline$l_{t}, l_{t}^{C B}$ & social loss function and the central banker's loss function \\
\hline$l_{s}^{C}, l_{s}^{N}$ & social loss functions with and without an active contract in state $s$ \\
\hline$V_{s}(C), V_{s}(N)$ & expected discounted intertemporal social losses in state $s$ with and without contract \\
\hline$f(b)$ & a function of $b$ \\
\hline$\hat{f}, \hat{b}$ & threshold values below which the ZLB is binding \\
\hline$f^{*}, b^{*}, b^{* *}$ & optimal designs of the contract \\
\hline$\hat{r}_{L}$ & threshold value below which the ZLB is binding regardless of the value of $b$ \\
\hline$r_{L}^{c}$ & threshold value below which the optimal value of $b$ is infinitely large \\
\hline$\tilde{f}$ & threshold value regarding the government's behavior \\
\hline$A, B, P, Q$ & constants \\
\hline $\bar{r}_{L}$ & the maximum possible realization of $r_{L}$ in uncertainty scenario \\
\hline$\tilde{b}, \tilde{r}_{L}, \tilde{r}_{L}^{c}, a$ & values in uncertainty scenario \\
\hline
\end{tabular}


Table 3: List of variables and notations (2)

\begin{tabular}{|c|c|}
\hline Variables & Description \\
\hline \multicolumn{2}{|c|}{ AlternativeSetup } \\
\hline$\pi_{L 0}^{C}, x_{L 0}^{C}, i_{L 0}^{C}$ & $\begin{array}{l}\text { inflation, output gap, and interest rate in state } L \\
\text { with an active contract in period } 0\end{array}$ \\
\hline$\pi_{L 1}^{C}, x_{L 1}^{C}, i_{L 1}^{C}$ & $\begin{array}{l}\text { inflation, output gap, and interest rate in state } L \\
\text { with an active contract in period } 1\end{array}$ \\
\hline$A_{0}, B_{0}, A_{1}, B_{1}$ & constants \\
\hline$V_{L A}(C)$ & expected discounted intertemporal social loss with an FGC \\
\hline$l_{L 0}^{C}, l_{L 1}^{C}$ & $\begin{array}{l}\text { social loss function with an active contract in state } L \\
\text { in periods } 0 \text { and } 1 \text {, respectively }\end{array}$ \\
\hline$\hat{r}_{L A}$ & $\begin{array}{l}\text { threshold value below which the ZLB is binding } \\
\text { regardless of the value of } b\end{array}$ \\
\hline$r_{L A}^{c}$ & threshold value below which the optimal value of $b$ is infinite \\
\hline \multicolumn{2}{|l|}{ Proof } \\
\hline$\hat{\pi}_{L}^{C}, \hat{x}_{L}^{C}, \hat{l}_{L}^{C}$ & $\begin{array}{l}\text { inflation, output gap, and loss function in state } L \text { with an active contract, } \\
\text { assuming the ZLB is not binding }\end{array}$ \\
\hline$X, Y \in C, N$ & $X$ represents whether a contract was signed in previous period \\
\hline $\begin{array}{l}\pi_{s}^{X Y}, x_{s}^{X Y}, l_{s}^{X Y} \\
a_{1}-a_{5}, \Delta_{1}, \Delta_{2} \\
z(b)\end{array}$ & $\begin{array}{l}Y \text { represents whether a contract is signed in the current period } \\
\text { inflation, output gap, and social loss function in state } s \\
\text { constants } \\
\text { function of } b\end{array}$ \\
\hline \multicolumn{2}{|c|}{ Microfoundation } \\
\hline $\bar{w}$ & fixed wage the central banker receives when no FGC is in effect \\
\hline$w_{t}^{C B}, \bar{w}^{C B}$ & $\begin{array}{l}\text { wage the central banker receives when FGC is in effect } \\
\text { and its global maximum }\end{array}$ \\
\hline$\tilde{i}_{t}$ & the deviation of the interest-rate choice from the forecast \\
\hline$\zeta\left(\tilde{i}_{t}\right)$ & a function of $\tilde{i}_{t}$ \\
\hline$C_{t}^{C B}$ & central banker's consumption \\
\hline$u\left(C_{t}^{C B}\right)$ & central banker's utility from consumption \\
\hline$\alpha$ & the weight of central banker's altruism towards households \\
\hline
\end{tabular}

